\title{
MAIORINA GLORIA ROMANORUM. MONEDAS, TESOROS Y ÁREAS DE CIRCULACIÓN EN HISPANIA EN EL TRÁNSITO DEL SIGLO IV AL SIGLO V *
}

\author{
POR \\ JUAN JOSÉ CEPEDA \\ Universidad de Cantabria. Santander
}

PALABRAS CLAVE: Moneda de bronce tardorromana. Circulación monetaria. Aprovisionamiento de moneda. Depósito monetal. Metrología. Cecas tardorromanas orientales. Arcadio. Honorio. Teodosio. Siglos IV-v d.C.

KEY WORDS: Late bronze coins. Coin circulation. Money supply. Hoards. Weights. Late eastern Roman mints. Arcadius. Honorius. Theodosius. $4-5^{\text {th }}$ centuries AD.

\section{RESUMEN}

Los tesoros y depósitos que se forman con las últimas acuñaciones a nombre de Teodosio y sus hijos conforman uno de los horizontes de acumulación de numerario más nutrido de la Hispania antigua. Formando parte de él se encuentra un grupo mayoritario de depósitos de aes, pero también una importante lista de conjuntos de solidi de Arcadio y Honorio, que marcan el momento de inmovilización de la masa monetaria que circula en gran parte de la península Ibérica en los decenios iniciales del siglo V. En este artículo nos ocupamos del estudio de uno de los tipos más característicos de depósitos formados con denominaciones de bronce: aquél que incluye preferentemente en su composición las monedas de módulo aes 2 -maiorinae- acuñadas hasta el año 395. La distribución desigual de este tipo de evidencias sobre el conjunto de Hispania nos da pie para abordar el problema de la compartimentación económica del territorio, así como la determinación de los cauces probables seguidos en su distribución.

\section{SUMMARY}

Coin Hoards formed with the last issues in the name of Theodosius and his sons stand out as oneof the most important numismatic repositories of ancient Hispania. It comprises a large group of aes hoards and a non negligible list of solidi treasures of Arcadius and Honorius, marking the moment at which the Roman currency in Hispania was frozen, in the early 5 th century. This paper studies the most typical of the hoards formed with bronze coins: that which prefera-

${ }^{*}$ Este trabajo ha sido realizado con el apoyo de una beca de investigación del Departamento de Educación del Gobierno Vasco. Una primera versión del mismo, mucho más breve, fue presentada al Convegno internazionale "Vita e sopravvivenza delle monete antiche», Ravello, 1990 (no publicado). El autor agradece los comentarios y críticas de los profesores Javier Arce y Ramón Teja, así como las informaciones suministradas por Miguel Figuerola (Univ.de León), Teresa Marot (Gab. Numismàtic de Catalunya), Raquel Gil (Univ. de Córdoba) y António Faría (IPA, Lisboa), especialmente útiles en la confección de los apéndices que acompañan al texto. bly includes maiorinae -the so called AE 2- minted before 395. The unequal distribution pattern of these coins leads to the problema of economic compartimentalisation in the territory and to the probable distribution flows.

\section{PECUNIAE MAIORES}

El sistema monetario romano de los últimos decenios del siglo IV, si bien se encontraba estructurado preferentemente sobre la acuñación de valores en oro, mantenía aún viva la producción regular de una amplia gama de denominaciones en metal vil (básicamente cobre), utilizadas, como había sucedido en épocas pasadas, en las más diversas operaciones de cambio. Su origen seguía estando en un grupo relativamente numeroso de cecas, repartidas a lo largo del Imperio según criterios que tenían que ver sobre todo con las necesidades y conveniencias de la propia administración. En los años 390 eran doce las monetae publicae que se encargaban aún de la producción de los valores fraccionarios básicos. Conformaban una red paralela a la más restringida de las cecas comitatenses - a lo sumo uno o dos talleres que trabajaban simultáneamente en los dominios administrados por un Augusto- en las que se centralizaba la acuñación del oro y la plata ${ }^{1}$.

Dentro de lo que podríamos llamar el sistema de la moneda fraccionaria o menor, el escalón superior de las denominaciones acuñadas en esta época estaba ocupado por lo que hoy conocemos como aes 2 (fig. 1), una moneda de bronce que carecía ya de enriquecimiento argénteo y que era acuñada teóricamente a 1/60 de libra $(5,38 \mathrm{~g})$. En este sistema de denominaciones se incluían además dos tipos predominantes de pequeños módulos: el aes 3 , emitido a una talla teórica de 1/120 o 1/132 de libra, y el aes 4 producido a 1/240 de libra. Al igual que había sucedido en otros momentos del siglo IV - empezando por la Tetrarquía - en los que se intentó recrear un sistema de valores múltiples, el aes más pesado recibió el nombre común de maiorina, maior nummus o

1 M. Hendy, Studies in the Byzantine Monetary Economy, c.300-1450, Cambridge, 1985, pp. 371-94; 448-75. 
maior pecunia atendiendo a su situación en la escala de las denominaciones acuñadas ${ }^{2}$. En contenido metálico representaba aproximadamente el doble y el cuádruple de los otros dos valores. Su producción, reiniciada por Graciano entre los meses finales del 378 e inicios del año siguiente, quedó interrumpida en todo el Imperio hacia el 386, para conocer un renacimiento posterior en las cecas orientales, entre el advenimiento de Honorio y la muerte de Teodosio I $(393-395)^{3}$. Es precisamente este último estadio en la producción regular de la maiorina el que ahora nos interesa, por ser uno de los que mejor se encuentra representado entre los hallazgos monetarios que periódicamente afloran en Hispania.

\section{ESTRUCTURAS MONETARIAS}

Hispania es pródiga en el hallazgo de depósitos teodosianos y, dentro de éstos, destaca por su frecuencia el grupo de los que se cierran con las últimas maiorinae del siglo Iv. Su número es tal que llega a conformar un horizonte sin parangón en ninguna otra parte del Imperio. La pérdida de estos depósitos no es, sin embargo, un hecho aislado, ya que guarda una estrecha relación con otras formas de atesoramiento que afectan al resto de los valores del sistema monetario (empezando por el solidus áureo) y que debemos relacionar, en la parte occidental del Imperio, con el clima de inestabilidad que se abre en el siglo v tras la usurpación de Constantino III (407411). En lo que respecta a la maiorina podemos apreciar su importancia en la composición de los depósitos de esta época con una simple ojeada a la relación que acompaña a este estudio. En el catálogo que allí aparece hemos podido reunir - sobre un total de cincuenta y cuatro- cuarenta y un conjuntos que, si bien están descritos demasiadas veces de forma incompleta, permiten reconocer la presencia dominante de este tipo de denominaciones. Un grupo más reducido, formado con depósitos muy modestos de composición menos discriminatoria, muestra

${ }^{2}$ C.Th. IX, 23, 1; a.354. IX,23,2; a.395.

3 Existen discrepancias notables a la hora de reconstruir el sistema monetario de estos años, cf. P. Bastien, Le monnayage de l'atelier de Lyon. Du règne de Jovien à la mort de Jovin (363-413), Wetteren, 1987, pp. 88-100; G. Depeyrot, «Le système monétaire de Diocletien à la fin de l'Empire romain», $R B N 138,1992$, pp. 79-81, 84-5. En lo que respecta al peso de las distintas denominaciones, el del aes 4 osciló considerablemente, aunque a finales de siglo representaba sin duda $1 / 240$ de libra (ca. 1,34 g); ver. J. Lallemand, «Trésor de petits bronzes romains découvert en Égypte: Constance II-Constant à Arcadius-Honorius», Chronique d'Égypte, 48,1973 , pp. 166-7; el peso más común para el aes 2 fue el de 1/60 de libra, el único en vigor en los últimos estadios de su acuñación (cf. infra apéndice 3). igualmente su difusión, entremezclada en un medio circulante heterogéneo, a menudo dominado por las emisiones de la familia constantiniana.

En su mayor parte, los depósitos conocidos reflejan una acumulación selectiva, muy homogénea, centrada en los tipos acuñados durante el reinado de Teodosio. El proceso de formación se puede seguir detalladamente en siete de ellos, cuatro completos - Garciaz, Torrecaños, Tróia de Setúbal y Palmar de Troya-y tres - Quintanas, Mata Lobinhos y Chão Barroso- con muestras suficientemente representativas. Más del $90 \%$ de sus contenidos se incluye siempre en el período de acuñación 379-395, mientras un porcentaje muy modesto viene ocupado por monedas anteriores de módulo similar que, de forma casi marginal, continuaban en circulación entre los años finales del siglo Iv y los decenios iniciales del v. En esta porción se incluye también un reducido número de ejemplares obsoletos o que han pasado la selección impuesta de manera fortuita.

El perfil de los depósitos señalados es en todos ellos muy similar (apéndice 2). Un primer bloque, que supone casi el 50\%, corresponde a los aes $2 \mathrm{Re}$ paratio Reipub (fig. 1: 1) emitidos a nombre de Graciano, Valentiniano II y Teodosio, completados con la serie del mismo tipo acuñada en las cecas gálicas por Máximo entre el 383 y el $386{ }^{4}$. Es de subrayar la

${ }^{4}$ No existe acuerdo sobre la fecha concreta en que se inicia la serie, que es en cualquier caso posterior a la muerte de Valente en agosto de 378 . Las posiciones se dividen actualmente entre quienes destacan la directa vinculación de la leyenda - Reparatio Reipub(licae) - y el tipo - el Emperador levantando a una alegoría de la Res Publica - a la derrota de Adrianópolis (378) y son partidarios por tanto de situar las primeras emisiones en el curso de los años 378/379 (J.W.E. Pearce, RIC IX, pp. xviii, xxi, xl y 7; J.P.Callu, «Reparatio Reipub: un problème de circulation monétaire», Nummus, 1 , 1978 , p. 100), y quienes prefieren retrasarlas hasta hacerlas coincidir con la introducción del aes 4 que celebra los vota quindecennalia de Graciano en el 381 (Bastien, Le monnayage de l'atelier de Lyon.. cit. n. 3, pp. 55-6 y 86-7); la reiteración de las marcas de exergo hace difícil, en cualquiera de las dos opciones, establecer una secuencia firme para la acuñación simultanea de los distintos valores. El aes 2 con reverso Reparatio fue producido abundantemente en las cecas situadas en los dominios de Graciano y sólo esporádicamente en las de Teodosio, lo que prueba su origen occidental; el intento de Carson y Kent (Late Roman Bronze Coinage II, Londres, 1960, pp. 42-3) de hacer coincidir las emisiones de Tesalónica, que calcan el modelo de los talleres más occidentales, con el período en el que las provincias del Illyricum oriental estuvieron en manos de Graciano, que ellos sitúan entre el 381 y el 383, y de retrasar por tanto a esa fecha el inicio de la serie es, a todas luces, demasiado forzado. Como se desprende de los trabajos de J.P.Callu, l.c., y especialmente D.Vera, «La carriera di Virius Nicomachus Flavianus e la prefettura dell'Illirico orientale nel IV secolo», en Athenaeum, 61, 1983, pp. 404-15, los cambios producidos en la diócesis de Macedonia y su capital no pueden ser considerados a la hora de fijar el inicio de la serie, ya que la región se mantuvo en la órbita de Teodosio hasta el 383, si no hasta el año siguiente. 


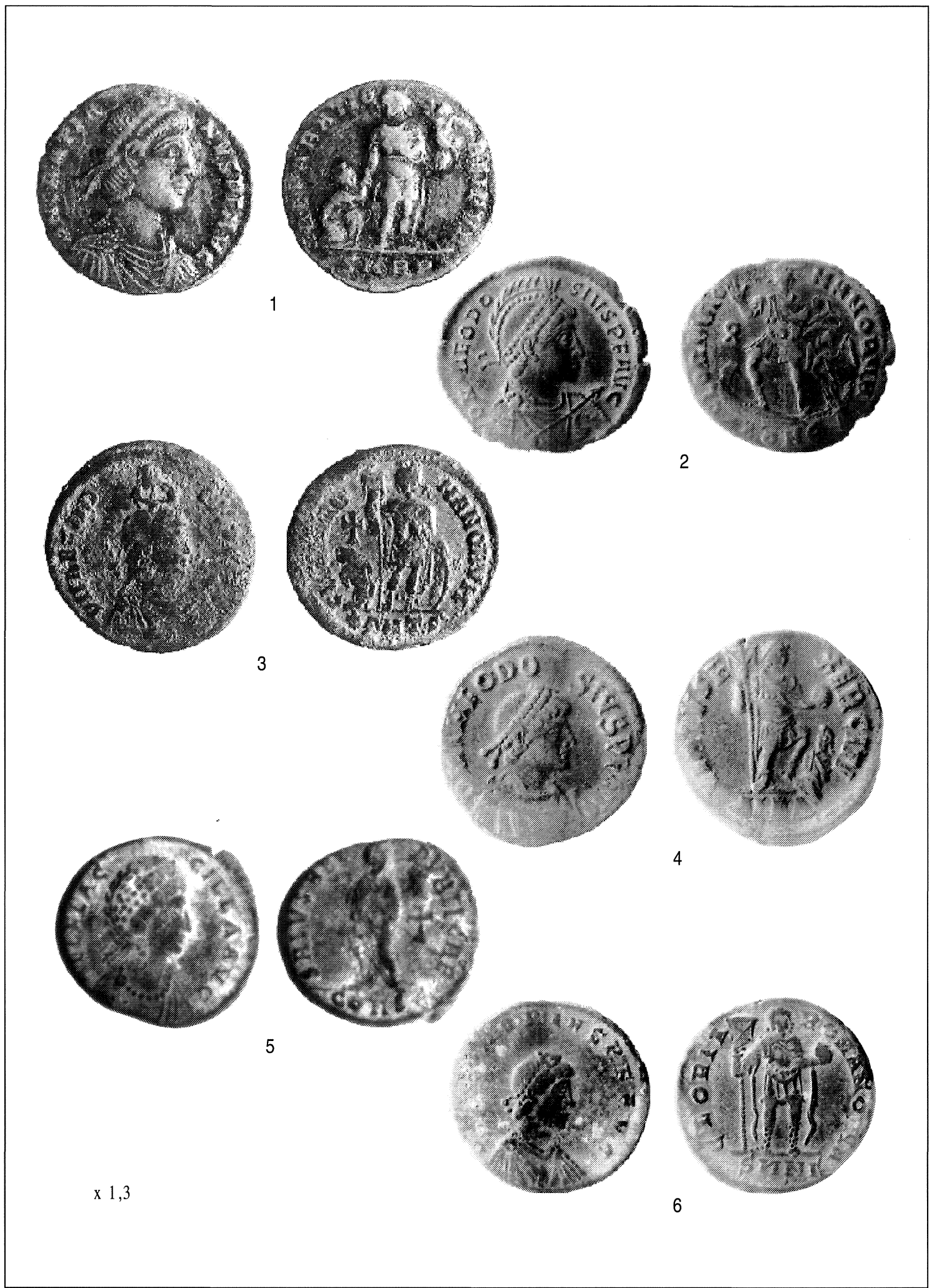

Fig. 1.-Aes 2. Tipos acuñados entre los años 379 y 395 d.C 
ausencia en este primer grupo de cantidades significativas de piezas emitidas con el mismo módulo en los dominios de Valentiniano y Teodosio durante los años que duró la usurpación, debida sin duda a la disminución simultánea de los contactos marítimos con Occidente ${ }^{5}$. A este núcleo de Reparatio Reipub se añade finalmente la serie Gloria Romanorum - Emperador con globo y labarum (fig. 1: 6) — producida en los talleres orientales entre enero del 393 y la muerte de Teodosio, acaecida en Milán el 17 de enero del $395^{6}$. A pesar de la lejanía de los lugares de procedencia y del corto lapso de tiempo que duró su emisión, hasta su desmonetización en abril de aquel año, los Gloria Romanorum participan en la composición de los depósitos en un volumen tan importante como el de la serie anterior, lo que es indicativo de la notable reactivación que conoció el tráfico marítimo entre los dos extremos del Mediterráneo en los últimos años del gobierno de Teodosio.

La repetición casi calcada de la estructura que hemos descrito líneas atrás en los depósitos inventariados - extensible también en sus líneas generales a conjuntos muy modestos, como sucede con los hallados en Fiães, San José, La Balsa, Camporrobles y Blanco Belmonte- nos habla sin duda de la homogeneidad de partida que mostraba la masa de aes 2 utilizada en una amplia zona de la Península. Ciertamente su difusión fue amplia, a juzgar no sólo por la dispersión de los depósitos sino por la misma abundancia de las maiorinae entre los hallazgos de circulación, donde a menudo superan en número a las monedas de módulo inferior acuñadas en el mismo período. La selección de los módulos, motivada seguramente por el valor otorgado a estas monedas y por la comodidad que entrañaba su uso, sirve también para desechar las abundantes emisiones de nummi tardoconstantinianos, de peso sensiblemente inferior, que eran aún de uso corriente a finales de siglo.

El interés selectivo explica precisamente que sea el año 395 el que marque un terminus post quem común para la mayor parte de los depósitos. Más allá de esta fecha tanto Occidente como Oriente sólo producen con regularidad aes 3 y aes 4 -este último

\footnotetext{
5 Callu, cit. n. 4, pp. 105-6; reversos Gloria Romanorum - con los tipos de la galera y el cautivo (fig.1: 2,3)—Salus Reipublicae (fig. 1: 5) y Virtus Exerciti (fig. 1: 4), producidos en las cecas al este de Aquileya entre inicios del 383 y el 385. Sobre las implicaciones históricas de los tipos adoptados por Teodosio, ver ahora H.R. Baldus, «Theodosius der Grosse und die Revolte des Magnus Maximus - das Zeugnis der Münzen», Chiron, 14, 1984, pp. 178-88.

6 J.P.C. Kent, RIC X, Londres, 1994, p. 68, sugiere que la acuñación pudo haberse continuado en Constantinopla algún tiempo después de anunciarse la muerte de Teodosio, ya que se conoce un ejemplar a nombre de Honorio con cesura en la leyenda de anverso.
}

será el módulo predominante durante el siglo $\mathrm{v}-\mathrm{y}$ los usuarios pudieron haber prescindido de estos valores mientras circulasen en su medio habitual piezas más atractivas para la tesaurización como las maiori$n a e^{7}$. Algunos indicios, dentro de los mismos depósitos, permiten entrever efectivamente la perduración de estas monedas en los decenios iniciales del siglo v. El tesoro de Torrecaños, que es uno de los más representativos de entre los hallados en la Lusitania, contiene un solidus de Honorio acuñado en Roma en los años 404-408; dos aes 3 aislados, pertenecientes a la serie Virtus Exerciti de Arcadio (395-401), cierran los depósitos de Las Quintanas y Chão Barroso, y un aes 4 de Tréveris sitúa el término para la constitución del pequeño conjunto de Manilva ca. 397. Estas monedas son siempre elementos aislados, que podemos calificar incluso de extraños en un perfil abrumadoramente dominado por los aes 2 . Aunque nos ayudan a llevar la clausura de los conjuntos al momento en que se interrumpe la provisión regular de moneda de bronce en buena parte de la Península, en los albores del siglo $\mathrm{v}$, su ausencia en la mayor parte de los casos no es indicativa de mayor antigüe$\mathrm{dad}^{8}$. Otro indicio que nos hace pensar que este tipo de monedas continuaba circulando de la Península años después de su acuñación, lo encontramos en la elección de nominales efectuada por Máximo durante su efímera usurpación, en el transcurso del 411. En esa fecha, en una ceca establecida en Barcino, volvió a acuñarse el viejo tipo Reparatio Reipub de Graciano ahora con la leyenda Victoria Auggg. Es bastante probable que de no haberse mantenido en uso estos

7 En las cecas administradas por Honorio sólo escapa a esta norma la rarísima emisión efectuada en Roma (ca.418) con el reverso Reparatio Reipubl (RIC X, p. 337 n. $\left.{ }^{\circ} 1354\right)$.

8 Es de lamentar que, salvo en contadas excepciones, no dispongamos de apreciaciones explícitas sobre el desgaste de las monedas, al haber sido publicados los conjuntos mejor conservados y más cuantiosos sin información metrológica o con pesos poco precisos (caso de Torrecaños, por ejemplo). Durante una breve visita al Museo de Salamanca, observamos que los ejemplares pertenecientes a Las Quintanas presentaban signos de desgaste en su superficie (la relación detallada se encuentra ahora en M.G. Figuerola, «El depósito monetal de Las Quintanas, Armenteros (Salamanca)», Numisma, 236, 1995, pp. 89-122), así como otras alteraciones, entre las que destaca la perforación de dos reversos Gloria Romanorum (393-395), una práctica relacionada con la disposición de las monedas en forma de «collares», que se documenta frecuentemente en el siglo V; cf. J.J.Cepeda, «Due ripostigli monetali di v secolo d.C. rinvenuti a Roma. Villa Giulia, 1922; Pratica di Mare, 1967», Bol. Num., 16-17, 1991, catálogo: 3,1\% en Villa Giulia y $1,7 \%$ en Pratica di Mare; porcentajes superiores al $10 \%$ en los depósitos africanos recopilados por P. Salama, «Économie monétaire de l'Afrique du Nord dans l'Antiquité tardive», Histoire et archéologie de l'Afrique du Nord (BACTHS, 19, 1983), Paris, 1985, p. 197, n.54. El desgaste es ocasionalmente señalado en algunas publicaciones de depósitos más modestos, así P. P.Ripollés, «Hallazgos numismáticos, 1984», Saguntum, 19, 1985, p. 322 (La Balsa). 
módulos, tal elección no habría tenido lugar ${ }^{9}$. En el mismo sentido podemos señalar que los aes 2 empiezan a aparecer cada vez con más frecuencia en contextos arqueológicos bien fechados con producciones cerámicas africanas del siglo v. El más revelador, sin duda, es el que corresponde a la excavación de la parte alta de la ciudad de Tarraco, donde se puede reconocer su uso - al menos su amortización en un vertedero- en el segundo cuarto de ese siglo ${ }^{10}$.

\section{CECAS}

Aunque los depósitos aquí estudiados se encuentran distribuidos por un sector importante de la Península, sólo un número limitado de ellos, procedentes generalmente de la Lusitania, incluyen una cantidad suficiente de monedas para llevar a cabo un estudio pormenorizado de su origen. Esta limitación geográfica no es nueva, ya que afecta de una manera general a buena parte de las ocultaciones monetarias del siglo IV.

Los depósitos examinados tienen un perfil muy influido por la presencia de los aes 2 de Teodosio. Es comprensible, por tanto, que el cómputo global de cecas arroje un saldo netamente favorable a los talleres orientales (cf. apéndice 2). Los dos bloques mayoritarios - Reparatio Reipub y Gloria Romanorum - responden, sin embargo, a dos estadios sucesivos en la circulación, que la fase final de la tesaurización ha mezclado definitivamente. El más antiguo lo forman monedas entremezcladas por el uso prolongado en la propia Península, en la que se han ido introduciendo progresivamente emisiones de Graciano y del usurpador Máximo, ampliamente difundidas en esta parte del Imperio. El estadio final lo conforma un bloque homogéneo de moneda oriental, introducido en un lapso de tiempo considerablemente inferior, que reproduce un patrón muy constante en la distribución de las cecas. A la hora de estudiar el origen geográfico se hace necesario, por tanto, distinguir estos dos grupos de acuñaciones.

El primero de los dos bloques señalados reproduce el desequilibrio ya conocido entre las cecas occidentales, que emiten abundantemente los reversos Reparatio, y los talleres de Teodosio, que adop-

9 Sobre la moneda de Máximo, T. Marot, «Algunas consideraciones sobre la significación de las emisiones del usurpador Máximo en Barcino», en R.Teja, C.Pérez, (eds.), Actas del Congreso Internacional la Hispania de Teodosio, II, Salamanca, 1997 , pp. 569-79.

10 Se trata de 15 aes 2 (379-395) sobre un total de 26 ejemplares; J.M. Carreté, «Les monedes», en TED'A, Un abocador del segle $v d$.C. en el forum provincial de Tarraco, Tarragona, 1989 , pp. 377-82; T. Marot, cit. n. 9, p. 574, corrige la atribución de uno de estos ejemplares, que corresponde a la usurpación de Máximo en la Tarraconense. tan el tipo occidental de manera mucho más restringida, hasta el 383, en Constantinopla, Nicomedia, Antioquía y Alejandría ". La inclusión de la diocesis Hispaniarum en los dominios de Máximo, que emitió únicamente piezas de módulo aes 2 en las Galias, hace a su vez que en el cómputo general del período sean precisamente los talleres allí emplazados los que refuercen su presencia.

Esta marcada incidencia de las cecas gálicas, que proporcionan como media el $50 \%$ de las monedas, se beneficia sin duda de los efectos restrictivos que tiene sobre la circulación de la época la usurpación de Máximo. Por su cercanía, volumen de producción y seguramente también porque sigue desempeñando entonces la función de proveedor primario de la moneda que se usa en Hispania, el taller de Arlés destaca sobre todos los demás. Su preeminencia se hace notable gracias fundamentalmente a las producciones del usurpador, ya que es durante su mandato cuando la ceca se convierte en la fuente fundamental de moneda divisionaria para todo el Occidente. El 70\% del aes de Máximo contenido en Las Quintanas tiene esta procedencia.

El segundo de los bloques aquí examinados está formado por los Gloria Romanorum de finales de siglo. En la distribución por cecas observamos una notable atomización, que se reproduce en parecidos términos en todos los depósitos conocidos. El reparto muy equilibrado de las producciones del área de los Estrechos, con Constantinopla y Nicomedia a la cabeza, y la presencia de un porcentaje siempre importante de la ceca de Antioquía, nos sitúa verosímilmente ante el reflejo de los respectivos volúmenes de acuñación de los talleres. Una comparación del orden de importancia de los porcentajes con el número de officinae utilizadas por cada uno de ellos sirve también para reforzar esta impresión. Constantinopla - la ceca mejor representada en tres de las muestras disponibles- y Antioquía - que arroja el cómputo total más elevado- acuñaron en cuatro officinae, mientras Cícico, claramente por debajo en su representación, cierra su cuarta dependencia en estos años ${ }^{12}$. La baja producción de Alejandría ha sido tradicionalmente señalada por cuantos se han ocupado de la circulación monetaria en Oriente durante estos años y no es de extrañar su baja incidencia en depósitos alejados de su ámbito de difusión natural como son los hispánicos ${ }^{13}$.

11 Pearce, RIC IX, pp. xx-xxi e introduciones a las cecas.

12 Cf. infra apéndice 3.

13 En Egipto el taller alejandrino proporciona como media el $40 \%$ del numerario a lo largo de todo el siglo Iv; $\mathrm{cf}$. $\mathrm{H}$. Schubert, Studien zum spätrömischen Münzumlauf in Ägypten. 1. Folles und Aes-Schätze aus dem 4. Jahrhundert n.Chr.,(SFMA, Bd.2), Berlín, 1984, pp. 138-9. 
Período 378/379-387

\begin{tabular}{|c|c|c|c|c|c|c|c|c|c|c|c|c|c|}
\hline \multirow[t]{2}{*}{ Depósito } & \multirow[t]{2}{*}{ Total* } & \multicolumn{2}{|c|}{ Galia } & \multicolumn{2}{|c|}{ Arelate } & \multicolumn{2}{|c|}{ Roma } & \multicolumn{2}{|c|}{ Aquileia } & \multicolumn{2}{|c|}{ Illyricum } & \multicolumn{2}{|c|}{ Oriente } \\
\hline & & & $\%$ & & $\%$ & & $\%$ & & $\%$ & & $\%$ & & $\%$ \\
\hline Làs Quintanas & 243 & 53 & 21,8 & 90 & 37,1 & 48 & 19,8 & 12 & 4,9 & 21 & 8,6 & 19 & 7,8 \\
\hline Garciaz & 518 & 99 & 19,1 & 159 & 30,7 & 113 & 21,8 & 54 & 10,4 & 51 & 9,8 & 42 & 8,1 \\
\hline Torrecaños & 400 & 68 & 17 & 120 & 30 & 66 & 16,5 & 41 & 10,3 & 51 & 12,8 & 53 & 13,3 \\
\hline Tróia & 240 & 39 & 16,3 & 73 & 30,4 & 65 & 27,1 & 17 & 7,1 & 26 & 10,8 & 20 & 8,3 \\
\hline
\end{tabular}

* Total de monedas clasificables

Período 393-395

\begin{tabular}{|c|c|c|c|c|c|c|c|c|c|c|c|c|c|}
\hline \multirow[t]{2}{*}{ Depósito } & \multirow[t]{2}{*}{ Total* } & \multicolumn{2}{|c|}{ Heraclea } & \multicolumn{2}{|c|}{ Constantinopolis } & \multicolumn{2}{|c|}{ Nicomedia } & \multicolumn{2}{|c|}{ Cyzicus } & \multicolumn{2}{|c|}{ Antiochia } & \multicolumn{2}{|c|}{ Alexandria } \\
\hline & & & $\%$ & & $\%$ & & $\%$ & & $\%$ & & $\%$ & & $\%$ \\
\hline Las Quintanas & 220 & 24 & 10,9 & 45 & 20,5 & 45 & 20,5 & 29 & 13,2 & 60 & 27,2 & 17 & 7,7 \\
\hline Garciaz & 679 & 84 & 12,4 & 157 & 23,1 & 174 & 25,6 & 86 & 12,7 & 159 & 23,4 & 19 & 2,8 \\
\hline Torrecaños & 396 & 27 & 6,8 & 119 & 30,1 & 85 & 21,5 & 31 & 7,8 & 112 & 28,3 & 22 & 2,5 \\
\hline Conimbriga** $^{* *}$ & 119 & 19 & 16 & 31 & 26,1 & 23 & 19,3 & 15 & 12,6 & 28 & 23,5 & 3 & 2,5 \\
\hline Tróia & 240 & 28 & 11,7 & 49 & 20,4 & 65 & 27,1 & 27 & 11,2 & 61 & 25,4 & 10 & 4,2 \\
\hline Palmar & 45 & 8 & & 13 & & 9 & & 7 & & 7 & & 1 & \\
\hline
\end{tabular}

* Total de monedas clasificables.

** Depósitos y hallazgos de circulación.

Fig. 2.-Depósitos de aes 2. Distribución por cecas.

El que se pueda reconocer un reparto por talleres tan variado, pero a la vez tan constante en los depósitos y en las series de circulación más nutridas - los escasos datos reunidos para la Bética no difieren substancialmente de los recogidos en los abundantes conjuntos lusitanos- nos empuja a creer que el núcleo mayoritario de las monedas orientales pudo haber llegado a la Península previamente entremezclado. Este proceso debió de tener lugar en la propia cuenca del Mediterráneo - el origen geográfico del numerario habla en cualquier caso de zonas más cercanas al Egeo que a Egipto- sin apenas estadios intermedios hasta su irrupción en Hispania. Aunque no faltan paralelos en el Mediterráneo occidental para la circulación intensa del aes acuñado en la pars Orientis - como ha sido observado recientemente en la costa africana- es la marcada especificidad del horizonte hispánico la que aconseja adoptar esta interpretación ${ }^{14}$.

${ }_{14}$ La alta proporción de moneda oriental es característica del territorio africano durante esta época, tal como destacan P. Salama, J.P. Callu, «L'approvisionnement monétaire des provinces africaines au $\mathrm{IV}^{\mathrm{e}}$ siècle», en L'Afrique dans l'Occident romain, Roma, 1990, pp. 113-5. No obstante, a diferencia de lo que se observa en Hispania, se trata de pequeños módulos, generalmente aes 4 . Su llegada pudo haberse visto facilitada por la dependencia administrativa que se observa en la diocesis Africae respecto a la corte de Teodosio: entre los años 393 y 395, por ejemplo, las disposiciones contenidas en el Código Teodosiano referentes a estos territorios emanan todas de Constantinopla; vid. P. Salama, Bornes milliaires d'Afrique Proconsulaire. Un panorama historique du Bas Empire romain, Roma, 1987, pp. 8-9 y 88-9. Aún más, es bastante probable que el inicio de esta situación
En cierta medida la llegada de las maiorinae orientales, en las postrimerías del reinado de Teodosio, se nos muestra como un cambio de tendencia bien que efímero- en la situación que presentaba el medio circulante en Hispania. En vísperas de la instalación de Honorio en Occidente, la masa de moneda disponible mostraba signos evidentes de obsolescencia. Su escasa renovación es un hecho constatado en la mayor parte de las series de circulación publicadas, mientras en amplias zonas del territorio, mal comunicadas con el litoral mediterráneo, la situación se agravaba aún más por el divorcio acusado que existía ya respecto a las fuentes de aprovisionamiento continental más cercanas ${ }^{15}$. Ante este estado de cosas pudo haberse hecho conveniente y hasta necesario el envío de cantidades importantes de moneda, a través de lo que era sin duda la vía de acceso más fácil a la Península: la ruta mediterránea. Este drenaje de moneda desde los centros productores orientales estaba teniendo lugar precisamente en medio de una coyuntura política particularmente favorable para ello.

se pueda retrotraer a la caída de Máximo, en el 388 (cf. F. Paschoud, Zosime, Histoire Nouvelle II 2, París, 1979, pp. 444-5). La aplicación estricta, ya en el 395, de la desmonetización de los módulos mayores en la parte central del Imperio y el hecho de que los conjuntos africanos conocidos correspondan a fechas avanzadas del siglo $\mathrm{v}$, son responsables de que apenas encontremos rastro de la circulación de la maiorina.

${ }^{15}$ Cf. J.-P.Bost et alii, Belo IV. Les monnaies, Madrid, 1987, p. 90. 


\section{IV. ÁREAS DE CIRCULACIÓN MONETARIA, ÁREAS DE CIRCULACIÓN ECONÓMICA}

En los años en que se estaban produciendo las que iban a ser las últimas monedas fraccionarias que alcanzasen masivamente la península Ibérica, el Imperio romano se encontraba una vez más dividido. Eugenio, un rétor de origen senatorial que había sido elevado a la púrpura por Arbogasto en la Galia tras la oscura muerte de Valentiniano II, amenazaba seriamente las ambiciones dinásticas de la familia teodosiana sobre el conjunto del Orbe. Hispania no había podido substraerse a este nuevo escenario político, incorporándose, como la mayor parte de las provincias occidentales, a los dominios del usurpador ${ }^{16}$. La ruptura entre las dos partes Imperii se produjo de forma definitiva en los inicios del año 393 y habría de durar aún hasta la derrota del usurpador en la batalla - cargada de resonancias históricas- de las orillas del río Frígido, en septiembre del 394. Es a partir de esa fecha cuando hemos de suponer que se produjo la arribada masiva a las costas hispanas del numerario emitido por Teodosio, toda vez que con anterioridad, en una situación de enfrentamiento, se hace difícil imaginar una trasvase de moneda como el que refleja el volumen de hallazgos conocidos. Menos aún podemos concebir, antes de la caída del usurpador, un abastecimiento oficial dirigido desde la pars Orientis. Los límites temporales en los que se acota la llegada efectiva de las maiorinae orientales son, por lo tanto, ciertamente estrechos: entre septiembre del 394 y los meses iniciales del año siguiente. Con posterioridad a la muerte de Teodosio la situación política volvía a ser marcadamente incierta, con dos cortes imperiales enfrentadas por los problemas administrativos del Illyricum y por las pretensiones hegemónicas de Estilicón. El cese de la acuñación y la posterior desmonetización de la maiorina en abril del 395, señalan por tanto el punto final más verosímil para el margen de tiempo en que pudo haber tenido lugar este movimiento ${ }^{17}$.

16 Sobre la figura de Eugenio, Zósimo, IV, 54-58 (con los comentarios de Paschoud, cit. n. 14, pp. 454 ss.); cf. J. Szidat, «Die Usurpation des Eugenius», Historia, 28, 1979, pp. 490-94. La vinculación de la diocesis Hispaniarum a la causa del usurpador se encuentra reflejada en un epígrafe funerario hallado en Tarraco, que se fecha por el consulado del año 393: «consulatum Eugeni Augusti primu» (sic); G. Alföldy, Die Römischen Inschriften von Tarraco, Berlín, 1975, vol.I, p. 415, n944 (=AE, 1938, 25).

17 Es bien conocida la tirantez casi continua que se establece entre las dos cortes imperiales tras la muerte de Teodosio, que ha llegado a ser calificada de «guerra fría»; cf. A. Cameron, Barbarians and Politics at the Court of Arcadius, Berkeley, 1993, pp. 3-8, 309-10. En Italia se decretó incluso
No es aventurado sospechar, tras lo dicho, que la puesta en circulación del numerario oriental en suelo hispano, donde se situaban los orígenes familiares de Teodosio, contase con algún tipo de implicación política. Desde luego, la llegada masiva de moneda de origen oriental no era algo novedoso a esas alturas del siglo Iv. Ya unos años atrás, una vez sofocada la usurpación de Magnencio, se había producido una situación similar, de mayor proyección aún, puesto que los bronces a nombre de Constancio II inundaron entonces el conjunto del Mediterráneo occidental. Contra lo que se ha sugerido en alguna ocasión, no parece haber existido en la administración imperial freno alguno que limitase la posibilidad de efectuar envíos ordinarios de moneda a larga distancia como los aquí observados, superando los límites que imponían demarcaciones regionales tales como las diócesis y prefecturas. Dado que el control de los talleres públicos estaba centralizado en el officium de las Sacrae Largitiones, y dado también que era un solo comes el que lo controlaba cuando no existía una división efectiva del poder imperial entre varios augustos, podía ser factible que se produjesen estos movimientos cuando la necesidad o conveniencia lo dictasen ${ }^{18}$. Es bien sabido que no todas las diócesis en las que se dividió el Imperio desde Diocleciano contaron con su propia ceca. Hispania es el caso más representativo, pero también las provincias africanas muestran esa carencia durante la mayor parte del siglo Iv. Ante situaciones así, lo más razonable es pensar que las necesidades de liquidez se solventasen con el envío de numerario procedente de las cecas establecidas en el entorno próximo y, en el caso de Hispania, hemos de pensar inmediatamente en las enclavadas en la prefectura del pretorio de las Galias, al ser ésta la circunscripción administrativa superior a la diócesis. No obstante, estos talleres podían no estar siempre en disposición de cumplir con este cometido. En

el cierre de los puertos a todos aquellos navíos que llegaban desde la pars Orientis, tal como se recoge en C.Th. VII,16,1; a.408 (el bloqueo posiblemente fue efectivo sólo entre el 407-408).

18 Aun siendo augustos en vida de Teodosio, Arcadio y Honorio carecieron - por su corta edad-de competencias propias. Sobre la administración de las Sacrae Largitiones, $\mathrm{R}$. Delmaire, Largesses sacrées et res privata. L'aerarium imperial et son administration $d u I V^{e}$ au $V I^{e}$ siècle, Roma, 1989 , pp. 63-73 y 495-516 (talleres monetarios). En noviembre del 395 el puesto de CSL en Oriente estaba ocupado por un hispano, Hosio (Delmaire, ibid., p. 121).

19 Hay indicios que hacen pensar incluso que el volumen de producción de estos talleres pudo haberse visto comprometido por el desenlace de la usurpación de Eugenio; cf. R.Delmaire, «Un trésor d'aes 4 au musée de Boulogne-surMer (notes sur la circulation monétaire en Gaule du Nord au début du V $\mathrm{V}^{\mathrm{e}}$ siècle)», TM, 5, 1983, p. 162. 


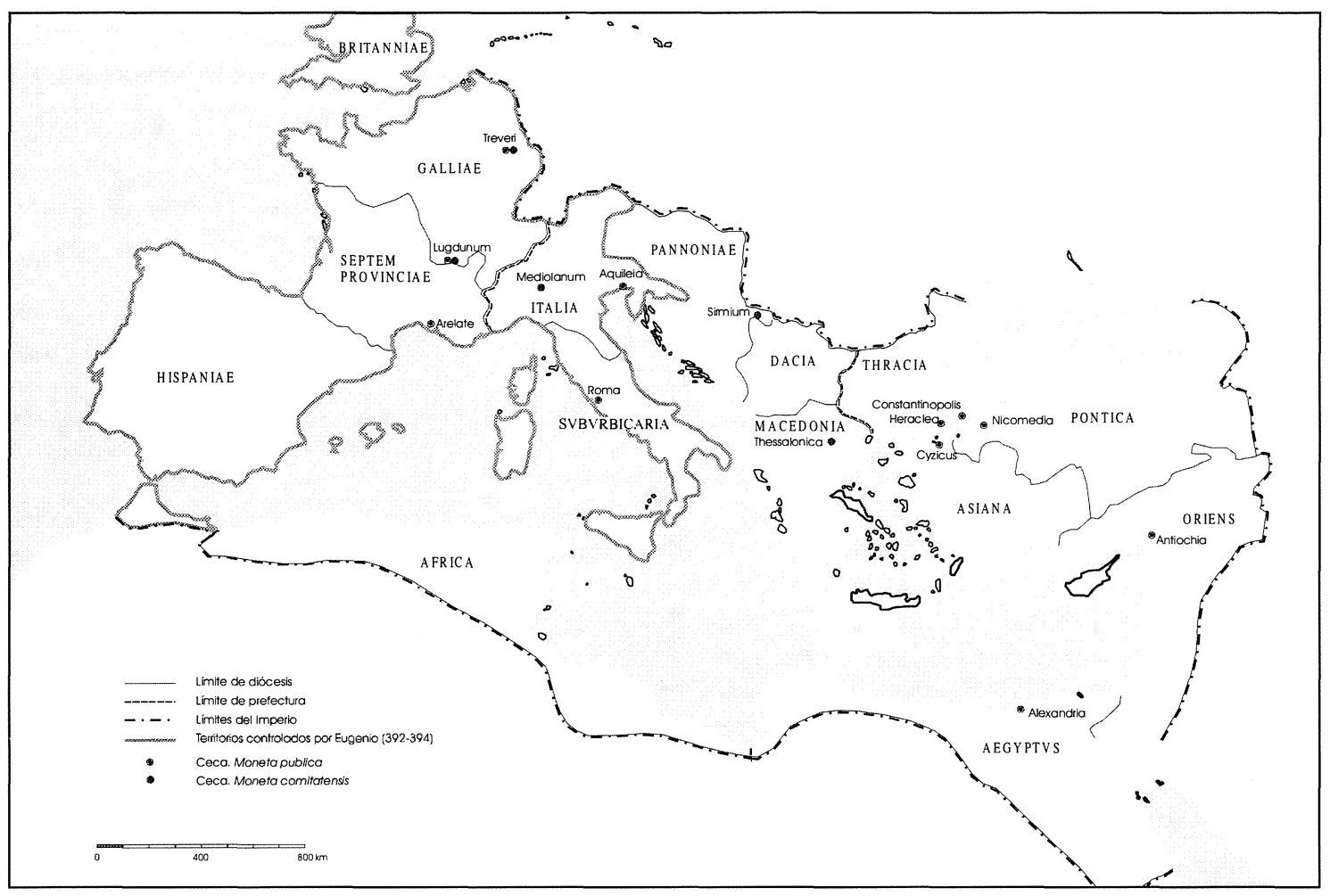

Fig. 3.-El imperio romano en los años 393-395. Cecas activas.

lo que respecta a las cecas gálicas, su actividad estuvo frecuentemente condicionada por la necesidad de abastecer regiones más septentrionales, fuertemente militarizadas y peor comunicadas con el centro económico del Imperio, que seguía estando en el Mediterráneo ${ }^{19}$. Tampoco hemos de olvidar que la prefectura, aún siendo el marco fundamental de la administración económica provincial, no fue nunca, en sentido estricto, el de la producción monetaria. Lo poco que sabemos de la geografía administrativa en la que se inserta la difusión de los productos de las distintas monetae publicae apunta en esa dirección ${ }^{20}$.

La posibilidad de que regiones carentes de ceca y con un fácil acceso a las rutas marítimas del Me-

20 A finales del siglo Iv Britania, dentro de la prefectura de las Galias, recibía casi la mitad del numerario de nueva acuñación de las cecas de Roma y Aquileya, fuera por tanto de esos límites. Ni siquiera durante la Tetrarquía, cuando más estrecha fue la vinculación entre las demarcaciones fiscales (diócesis) y la localización de las cecas, se traducía ello en la circulación: el límite para las áreas de difusión de las monedas quedaba definido frecuentemente por el control territorial que en la práctica ejercía cada uno de los augustos y por la proximidad relativa de los talleres en funcionamiento; cf. Hendy, Studies..., cit. n. 1, pp. 378-80; para Britania, P. Guest, «Hoards from the End of Roman Britain», en Coin Hoards from Roman Britain, X, Londres, 1997, pp. 415-21. diterráneo fuesen aprovisionadas desde Oriente en determinadas coyunturas del siglo IV no es descabellada. Ante circunstancias como las que se han señalado para el período de emisión de los Gloria Romanorum, en los que se estaba produciendo una efectiva reconquista del poder, esta respuesta parece más convincente que la tradicionalmente aducida de la difusión comercial, por muy bien que esté atestiguada la existencia de colonias de mercaderes sirios en las costas del levante y mediodía hispano ${ }^{21}$. El comercio interregional fue sin duda durante la Antigüedad un elemento uniformizador de los stocks monetarios a largo plazo, al menos en la cuenca del Mediterráneo occidental, pero no parece verosímil que en el siglo IV fuese capaz por sí solo de facilitar los aportes masivos de moneda que conforman a la postre el medio circulante provincial. La moneda de bronce no era en principio la más adecuada para el gran comercio, dado su bajo poder liberatorio y el gran volumen de carga necesario para su transporte. Es difícil de concebir por tanto que su suministro fuese una simple derivación del comercio practicado a larga distancia. La historiografía

${ }^{21}$ Sobre el particular, L.A.García Moreno, «Colonias de comerciantes orientales en la península Ibérica. Siglos V-VII», Habis, 3, 1972, pp. 127-54. 
reciente minimiza igualmente la importancia del transporte físico de la moneda en el contexto de las operaciones comerciales, ya que en general éstas podían efectuarse con un único movimiento en los puertos de llegada, una vez vendida la carga y adquiridos los productos de reembarque ${ }^{22}$. Hay que pensar por tanto en una intención determinada que propiciase el embarque de este numerario como objeto de transporte en sí mismo e hiciese posible su posterior difusión en Hispania y ello no pudo haberse realizado en ningún caso sin el propio consentimiento de la autoridad emisora ${ }^{23}$.

$\mathrm{Si}$ a partir de estas consideraciones bajamos al terreno de las evidencias numismáticas y volvemos la vista hacia el panorama que ofrece la dispersión de los depósitos localizados en Hispania, dos habrán de ser nuestros motivos de reflexión. Por una parte el que se deriva de la desigual presencia de la moneda oriental en el conjunto del territorio y, por otra, la escasa conexión que en los decenios iniciales del siglo $v$ parece existir, en lo referente al origen del numerario, entre la circulación del bronce y la del oro.

La primera de las dos cuestiones enunciadas está íntimamente relacionada con la existencia de patrones selectivos en la constitución de los depósitos, cuya documentación presenta igualmente peculiaridades geográficas destacables. La aplicación de criterios selectivos a la hora de reunir un grupo de monedas de uso corriente no era una novedad de esta época. A lo largo del siglo Iv las diferentes reformas de la moneda de vellón y bronce fueron propiciando la aparición de tipos específicos en la agrupación de las monedas, en los que podían intervenir tanto las rupturas impuestas sobre el sistema de denominaciones como las preferencias de los usuarios por uno $\mathrm{u}$ otro de los valores acuñados, cuando eran varios los que se incluían simultáneamente en el sistema monetario. No es en modo alguno extraño que diferentes tipos de tesoros y depósitos se documenten de forma contemporánea y que éstos puedan estar igualmente influidos por factores puntuales, que guardan relación con el fin de la acumulación o con

${ }^{22} \mathrm{Cf}$. Ch. Howgego, «Coin circulation and the integration of the Roman economy», JRA, 7, 1994, pp. 7-8, 14.

${ }_{23}$ Siempre queda la posibilidad de que, tal como se recoge en C.Th. IX, 23, 1 (a. 354), los mercatores que frecuentaban las rutas mediterráneas hubiesen contribuido a hacer más intenso el flujo de numerario, al especular con la diferente consideración que merecían las monedas en el medio provincial. A tal fin podían transportarlas bien en el transcurso de sus operaciones privadas o como complemento del servicio que eventualmente podían prestar a la administración. Este tipo de especulación estaba no obstante severamente penado, como indica el propio texto; cf. Hendy, Studies..., cit. n. 1, pp. 290-3. los condicionantes económicos que actúan sobre los responsables de la misma. La oposición, frecuente en la evidencia manejada a lo largo de este estudio, entre depósitos poco afectados por la selección - generalmente, aunque no siempre, de pequeña entidad y destinados a servir a un uso cotidiano- y las acumulaciones discriminatorias, que alcanzan en ocasiones el valor de uno o varios solidi, debe ser claramente relacionada con este proceso.

En el tiempo que nos ocupa, las acumulaciones selectivas tienen en el aes 2 posterior al 378 el elemento determinante de su composición y se diferencian bien de los depósitos con un contenido más heterogéneo que recoge el tout venant de la circulación, frecuentemente dominada por monedas de acuñación más antigua. En circunstancias especiales, cuando los hallazgos se han producido en el transcurso de excavaciones arqueológicas, se ha podido comprobar que estas dos actitudes conviven incluso en el mismo contexto, como es el caso de los dos depósitos recuperados en el castro de Fiães, que, aún siendo muy modestos, presentan perfiles netamente distintos; el primero compuesto mayoritariamente por aes 2 (poco menos del $80 \%$ ) y el segundo dominado por los nummi de la familia de Constantino abundantes aún en la circulación hasta fechas entradas del siglo v. No obstante estas coincidencias ocasionales, hay que destacar ya que la frecuencia y distribución geográfica de estos dos tipos de depósitos es muy desigual.

En principio no toda la Península parece haber dispuesto de cantidades importantes de aes 2 en su circulación como para propiciar posteriormente la aparición de un horizonte homogéneo de depósitos compuestos por esta denominación. Al norte del Duero y el valle medio del Ebro, los conjuntos con estas características son prácticamente inexistentes y es únicamente el tipo de acumulación formada por pequeños bronces -el mismo que convivía en el resto de la Península con los depósitos de maiorinae- el que se documenta ${ }^{24}$. Dentro de este horizonte se incluyen los importantes tesoros de Torre, Balboa y Galiana, pero también una larga lista de conjuntos de menor entidad o conocidos sólo por muestras parciales (fig. 4). Una vez descartado el factor cronológico como explicación de la formación de estos dos grupos de depósitos - ambos corresponden mayormente al momento de inmoviliza-

${ }^{24}$ Depósitos de pequeños bronces en las mismas zonas en que aparecen los aes 2: Conimbriga E y F (I. Pereira, J.P Bost, J. Hiernard, Fouilles de Conimbriga, III. Les monnaies. Paris, 1974, pp. 327-9), Italica II (F. Chaves, «Hallazgos numismáticos», en $\mathrm{P}$. León, Traianeum de Italica, Sevilla, 1988, pp. 121-37), Orippo (apéndice 1), entre otros. 


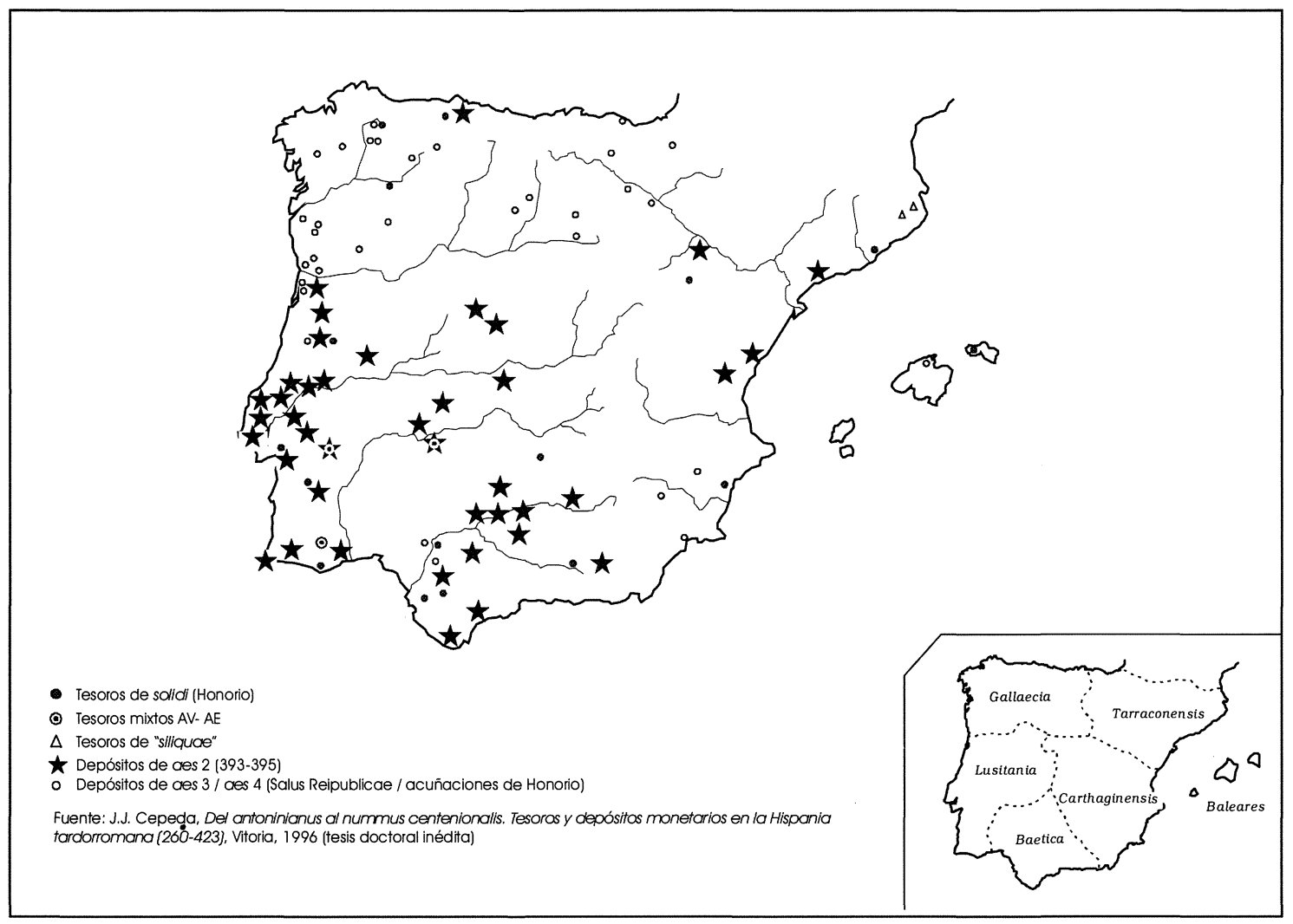

Fig. 4.-Depósitos monetarios (post 395).

ción de la masa monetaria en los primeros decenios del siglo v- sólo queda hablar de zonas de circulación distintas, con volumen y composición de la masa monetaria diferentes.

La explicación basada en la existencia de distintas áreas de circulación ha ido tomando cuerpo desde el momento en que se constató por vez primera la concentración de depósitos de aes 2 en la Lusitania y sigue siendo la más convincente de las posibles ${ }^{25}$. Hoy en día la dispersión de estos depósitos puede hacerse extensible a la Bética y fachada levantina de las provincias Tarraconense y Cartaginense, zonas todas ellas en las que abundan los testimonios materiales derivados de la actividad comercial mantenida entre los puertos mediterráneos y sus áreas de influencia en el interior. El indi-

${ }^{25}$ D. Nony, «Acerca de la circulación de la moneda en Lusitania a fines del siglo IV», XI CNA, Zaragoza, 1970, p. 833; Fouilles de Conimbriga, cit. n. 24, pp. 300 y 310. Las series de circulación también apuntan en el mismo sentido: la más numerosa de las muestras hoy disponibles para el norte de Hispania, procedente de la villa de La Olmeda (Palencia), muestra una total ausencia de aes 2 teodosianos; cf. M. Campo, Las monedas de la villa romana de La Olmeda, Palencia, 1990, passim. cador fundamental de la existencia de una tupida red de intercambios en esta zona lo constituye, sin duda, la difusión, bien documentada en términos generales, de la cerámica fina de mesa de origen africano, un producto que en sí no debió tener mucha importancia macroeconómica, pero que, por su carácter imperecedero, es un buen fósil guía para conocer la dirección y alcance de movimientos económicos más amplios ${ }^{26}$. Lo que nos interesa subrayar aquí es que tanto la difusión de este tipo de materiales como la circulación del aes 2 de finales del siglo iv coinciden en sus límites generales. Ello se explica bien si consideramos que, en su distribución secundaria, una vez puestas en circulación en los enclaves costeros y centros administrativos más importantes, las monedas siguieron las mismas rutas: los cursos fluviales del Ebro, Guadalquivir,

${ }^{26}$ Las cerámicas eran objeto seguramente de una comercialización secundaria desde los puertos, en compañía de otros productos de más volumen (vinos, aceites, textiles...); la contrapartida podría ser igualmente muy heterogénea. Sobre las motivaciones que pueden estar detrás de la amplia difusión de los productos cerámicos, ver en particular $\mathrm{C}$. Wickham, «Marx, Sherlock Holmes, and Late Roman Commerce», JRS, 1988, pp. 190-2. 
Guadiana y Tajo y las vías terrestres que confluían con ellos ${ }^{27}$. Una dirección perfectamente asumible para unas monedas que tenían su origen en las cecas enclavadas en las riberas del Mediterráneo y habían llegado por vía marítima a Hispania.

La casi total ausencia de depósitos con aes 2 de procedencia oriental en la mitad septentrional de Hispania sorprende menos si consideramos que son también estas regiones las que carecen de elementos en la cultura material que denoten intercambios con los puertos mediterráneos y sur-atlánticos de la intensidad de los observados anteriormente. Su alejamiento y las dificultades que se imponen en el tráfico terrestre se dejan notar en la circulación monetaria y en la composición de los depósitos, cuyas monedas difieren en ocasiones de las halladas en el sur y este de la Península no tanto en el origen último como en la calidad y volumen con el que están disponibles. La moneda es sin duda el producto que más rápido se mueve de un lugar a otro del Imperio pero en los trayectos interiores su circulación parece haber estado sujeta a compartimentaciones similares a las que se imponen en otros ámbitos de la vida económica ${ }^{28}$. No es por tanto ninguna casualidad que los depósitos que cuentan con una estructura más anquilosada se hallen en la Gallaecia, la región de situación más excéntrica y en la que los especialistas de la cultura material han detectado facies o subculturas definidas por la difusión restringida de determinados tipos de cerámica o ajuares metálicos, característica de espacios económicos fragmentados ${ }^{29}$.

27 Sobre los hallazgos cerámicos, R. Járrega, Cerámicas finas tardorromanas africanas y del Mediterráneo oriental en España. Estado de la cuestión (Anejos AEspA, 11), Madrid, 1991, pp. 90-5; J.A. Paz, Cerámica de mesa romana de los siglos III al vi d.C. en la provincia de Zaragoza, Zaragoza, 1991, pp. 232-5; M. Beltrán, Guía de la cerámica romana, Zaragoza, 1990, pp. 135-41. A juzgar por la distribución de estos productos, hemos de pensar que la costa lusitana se comportaba en lo económico como una prolongación del Mediterráneo.

${ }^{28}$ El panorama que ofrece la distribución de los depósitos muestra a fortiori la poca importancia que tiene la ruta marítima cantábrica como vía de acceso para la moneda y mercancías de origen mediterráneo. El único conjunto para el que se puede aventurar una composición similar a la de los hallados en la Bética y Lusitania, el de Colloto, es un elemento aislado, que se ha de relacionar con la proximidad de Gijón, la única ciudad portuaria del Cantábrico que se mantiene como tal durante la Antigüedad Tardía; cf. C.Fernández Ochoa, A.Morillo, «La ruta del Cantábrico en época romana», Zephyrus, 46, 1994, p. 226.

${ }^{29}$ Cf. L.Caballero, La necrópolis tardorromana de Fuentespreadas (Zamora), (EAE,80) Madrid, 1974, pp. 186-92, donde se defiende la existencia de una «subcultura del Duero»; fragmentación de espacios económicos y atrofia de los intercambios intra-regionales son por otra parte características que se señalan para amplias zonas del Imperio en esta época, vid. C.R.Whittaker, «Late Roman trade and traders», en P. Garnsey, K.Hopkins, C.R.Whittaker, Trade in the Ancient Economy, Londres, 1983, p. 179.
Queda por último abordar en este apartado la relación que pudiera existir entre la formación de los depósitos de aes aquí estudiados y los tesoros de solidi contemporáneos. Ante todo hay que advertir que las monedas de oro, a diferencia de lo que se aprecia en la circulación del bronce, continúan alcanzado el territorio peninsular en cantidades considerables hasta prácticamente la víspera de la ruptura de los lazos de dependencia administrativa con la corte imperial. Para buena parte del territorio provincial sabemos que ello tiene lugar poco después de la entrada de suevos, vándalos y alanos. Se comprende, por tanto, que en el interior de estos tesoros dominen de forma abrumadora las acuñaciones efectuadas por Honorio. El oro era objeto de una rápida refundición, al estar incluido como elemento fundamental en el mecanismo de reciclaje monetario que era la fiscalidad de la época y ello determina más que en los depósitos compuestos por otros metales la sobrerrepresentación de las emisiones más recientes. La continuidad en el flujo del oro facilita también la fechación de estos tesoros, que en su inmensa mayoría tienen términos de clausura posteriores al 402 . El contexto de formación debió de ser, en cualquier caso, el mismo que el que ha sido propuesto para los conjuntos de aes teodosianos, aunque la demora entre las fechas de emisión y la clausura de los conjuntos fuese menor ${ }^{30}$.

Si nos fijamos en el origen de las monedas que integran los dieciséis tesoros de solidi actualmente conocidos, apenas encontraremos una proporción menor de numerario oriental en su composición. Tan solo destacan al respecto los conjuntos de Seadur (tres solidi orientales sobre un total de cinco), Conimbriga (tres ejemplares sobre diez) y Chapipi (cuatro sobre trece). Este comportamiento está condicionado por la manera en que se organiza la acuñación del oro a finales del siglo Iv dentro del propio comitatus imperial, en una suerte de taller móvil que sigue los desplazamientos del Emperador. Así se entiende que en las fechas en que está teniendo lugar la emisión de los aes 2 orientales, los únicos solidi capaces de alcanzar Hispania en número importante fuesen los de origen occidental, tal como

${ }^{30}$ El repertorio más reciente es el de John Kent, $R I C X$, pp. xc-xcii, con atribuciones que con frecuencia corrigen las que aparecen en las publicaciones originales. A la lista habría que añadir ya los tesoros de Seadur y Viladonga; T. Vega, «Hallazgo de un depósito de solidi de Honorio y Arcadio en la villa romana de Seadur (Larouco, provincia de Ourense)», en Galicia: da romanidade á xermanización. Homenaxe a Fermín Bouza Brey (1901-1973), Santiago de Compostela, 1992, pp. 313-23; J.J. Cepeda, «El castro de Viladonga (Lugo). Los depósitos monetarios», Numisma, 236, 1995, pp. 29-63. 
marca la ruta seguida por Teodosio. Primero serán los que se producen en Sirmio y luego, a partir de septiembre del 394, tras la desaparición de Eugenio, los que se acuñen en Italia ${ }^{31}$. Teniendo en cuenta que en los momentos de máxima inmovilización de numerario, a partir de los años 410 , la masa monetaria se había incrementado ya con las acuñaciones de Honorio - dentro, por tanto, de un área de circulación específicamente occidental- debe sorprendernos poco encontrar en la mayor parte de los tesoros un dominio claro de los solidi de Milán (395-402) y Rávena (402-407; ca.410-420).

\section{LA VIDA DE LOS GLORIA ROMANORUM}

Entre las disposiciones de contenido monetario incluidas en el Codex Theodosianus figura una constitución de Honorio que afecta directamente al problema de la delimitación temporal y geográfica del uso de la maiorina. Aunque el texto ha sido citado en infinidad de ocasiones, creemos conveniente traducirlo y comentarlo en las líneas que siguen ${ }^{32}$.

«Los emperadores Arcadio y Honorio augustos, a Dexter prefecto del pretorio. Ordenamos que sólo el centenional (centenionalis nummus) sea usado en la circulación pública (in publica conversatione), dado que la fabricación de la moneda mayor (maior pecunia) ha sido interrumpida. Por tanto, que nadie ose cambiar el decargiro (decargyrus nummus) por otra moneda, sabiendo que debe ser reclamada por el fisco la moneda que haya podido ser encontrada en circulación. Dada el día antes de los idus de abril en Milán, en el año del consulado de Olibrius y Probinus (12 de abril, 395)».

El texto se ocupa de la circulación de los valores de bronce, que aparecen recogidos aquí bajo distintos nombres. De los términos utilizados, el genérico maior pecunia y el decargyrus se refieren seguramente a una misma moneda, que no puede ser otra que el aes 2 acuñado tiempo atrás en Occidente y mantenido hasta el 395 en Oriente. La utilización de un segundo nombre para designar a esta moneda responde a la necesidad de especificar el tipo concreto que sería objeto de retirada tras la aplicación de la ley. Para ello se emplea la forma latinizada de un término griego que podemos traducir como «moneda (argyron) de diez». Esta forma de llamar a la más alta de las denominaciones en

${ }^{31}$ Organización de la moneta comitatensis y sus desplazamientos en estos años, Delmaire, Largesses sacrées..., cit. n. 18 , pp. 508-15. No obstante, cf. J.P.C. Kent, «The Coinage of Arcadius (395-408)», NC, 1991, pp. 35-9, con los problemas que plantea el solapamiento en el tiempo de las distintas localizaciones propuestas para la ceca de Teodosio.

${ }^{32}$ C. Th. IX, 23, 2. curso es sin duda una herencia de tiempos pasados, cuando la maiorina valía efectivamente diez nummi. Su aparición se puede remontar quizás a la reforma del 348, que introdujo un aes 2 de contenido metálico enriquecido con plata igual al de diez de la unidades básicas de entonces (aes 3). Con mayor seguridad podemos entrever su uso durante el reinado de Juliano, cuando la moneda mayor era también de vellón y mantenía la misma relación metálica con el aes 3. A partir de entonces el decargiro debió de haberse convertido en una forma alternativa -más propia del lenguaje burocrático oficial - de designar a la maiorina, con independencia del valor real de ésta ${ }^{33}$. El tercero de los términos que aparecen en la ley -centenionalis nummus - designa en cambio a una denominación inferior, que es la que se mantiene en circulación. Se trata de un nombre ya conocido por otra disposición del Teodosiano (IX, 23,1; a.354) que permite su identificación con el aes 3 del período 348-358. El hecho de que la denominación intermedia siguiese acuñándose en Oriente a finales de siglo y usándose en Occidente aún a inicios del siglo v (como revelan los tesoros conocidos) sugieren que es éste el valor que hemos de seguir identificando con el centenionalis. La ausencia de mención a la última de las denominaciones en curso en la época -el aes 4- quizás se deba únicamente a que no ofrecía posibilidad de confusión alguna con la maiorina, el objetivo fundamental de la ley ${ }^{34}$.

La importancia de la constitución de Honorio radica en que, al menos para Occidente, manifestaba la voluntad de reforzar los efectos del cese de la acuñación del aes 2 con una retirada oficial de su curso. Seguramente ese objetivo sólo pudo cumplirse en las operaciones de carácter fiscal o de cambio

${ }^{33}$ Cf. K.W. Harl, Coinage in the Roman Economy, 300 $B C$ to $A D 700$, Baltimore, 1996, p. 174 (no tan acertado en otros aspectos); el uso de decargyrus nummus durante la aplicación de la reforma de Juliano es una fundamentada hipótesis de M. Munzi, «Considerazioni sulla riforma monetaria dell'imperatore Giuliano», AIIN, 43, 1996, pp. 302-4, a partir de Efraín Sirio (Hym. I contra Iulianum, 16-19). En Oriente, el término argyron hacía tiempo que había dejado de designar sólo a la moneda de plata. Primero da nombre a los bronces que cuentan con un plateado superficial (vellón) y luego de forma general se aplica a la moneda fraccionaria; ver R.S. Bagnall, Currency and Inflation in Fourth Century Egypt, (Bull. Am. Soc. of Papyrologists, suppl.5), Nueva York, 1985 , p. 45

${ }^{34}$ Hay que advertir de todos modos que no existe acuerdo unánime en la equiparación aes 3-centenionalis. A su favor, entre otros, P. Bastien, Le monnayage de l'atelier de Lyon... cit. n. 3, pp. 83-4 y 94-5; contra, Kent, RIC X, pp. 18-9 (aes 4). El aes 4 debió de recibir el nombre genérico de nummus (Nov. Val. XVI,2; a.445) y, en Occidente, denarius (así en $C$. Th. XIV,4,10; a. 419: precio de adaeratio de una libra de carne en 50 denarios). 
en las que intervenía la propia administración, bien a través de la recaudación o mediante el control sobre la actividad de los cambistas (nummularii). El ámbito geográfico de aplicación cierta fue la parte central del Imperio administrada por Nummius Aemilianus Dexter (PLRE I, Dexter 3), a la sazón prefecto del pretorio de Italia, África e Ilírico. Pueden ponerse serias objeciones a su operatividad más allá de estos límites, empezando por las que se derivan de nuestra incertidumbre sobre la «generalidad» con la que eran aplicadas las disposiciones contenidas en el Codex Theodosianus ${ }^{35}$. En tal sentido, parece poco probable que el horizonte de depósitos documentados en Hispania pueda ser relacionado con los efectos de la ley, como una respuesta cercana con la que se pretendiera eludir la relación de cambio desfavorable o la llana confiscación. Ya se ha hecho notar páginas atrás cómo la información que éstos reportan nos habla de la continuidad del uso de la maiorina dentro del siglo v. En las zonas en las que sabemos se aplicó literalmente la medida, como Italia y África, la retirada de las piezas que, con estas características, pudieran estar eventualmente en uso se realizó sin traumas aparentes. Su retirada no parece haber dado lugar a ninguna ola de acaparamiento, aunque sus efectos fuesen duraderos y se puedan reconocer hoy en el perfil de los depósitos de fechas avanzadas del siglo $\mathrm{v}$, monopolizados en su composición por el aes $4^{36}$.

Lo más verosímil es que los depósitos peninsulares fueran formados una vez iniciado el siglo $\mathrm{v}, \mathrm{y}$ que la retirada oficial de la maiorina no fuese efectiva o tuviera lugar de forma poco rigurosa y breve en el tiempo. La concentración de los hallazgos en las zonas occidentales de la Lusitania y Bética sugiere que en su mayor parte son posteriores a la crisis desatada con la «invasión» germánica del 409. En ambas regiones está bien documentado el paso o asentamiento de vándalos, alanos y suevos, causa más que probable del clima de inseguridad que condicionó la no recuperación de los conjuntos ${ }^{37}$. Constitu-

${ }^{35}$ En el momento en que se estaba confeccionando el Código ya se introducían provisiones contradictorias respecto al carácter «general» de las disposiciones que habrían de recogerse $(C$. Th. I, 1,6; a. 435). Lo único cierto es que el ámbito original de aplicación de las constitutiones dirigidas a los prefectos del pretorio era el territorio que éstos administraban directamente. Ver J. Matthews, «The Making of the Text», en J. Harries, I. Wood (eds.), The Theodosian Code, Londres, 1993, pp. 26-9, y, en el mismo volumen, B. Sirks, "The Sources of the Code», pp. 51-8.

36 Cf. J.P.C. Kent, «The Italian bronze coinage of Valentinian III and a hoard of fifth-century Roman bronze coins from El-Djem, Tunisia», Studia Numismatica Labacensia A. Jelocnik Oblata (Situla, 26), Ljubiana, 1988, pp. 190-3 (relación de depósitos italianos y africanos); P. Salama, J.P.Callu, «L'approvisionnement monétaire...», cit. n. 14, p. 115. yen, en suma, el contrapunto de los depósitos de pequeños bronces aparecidos en la Gallaecia y norte de la Península, territorios en los que es la baja cantidad de piezas circulantes con estas características, más que su retirada forzosa, la que explica las diferencias.

En la actualidad resulta difícil y ciertamente arriesgado proponer unos límites precisos a la circulación de los bronces de época teodosiana que encontramos en Hispania. Ya se ha señalado que la moneda fraccionaria romana deja de llegar — salvo contadas excepciones- entre finales del siglo IV y los años iniciales del siglo siguiente. El horizonte monetario hispano se suele cerrar, por tanto, con los ejemplares que aquí estamos estudiando y con los nummi de módulo aes 4, tipo Salus Reipublicae, producidos en el período 388-402. Incluso dentro de esta última serie son raras las monedas que pueden ser atribuidas con certeza al reinado de Honorio (tipo RIC X, 1238; 1247). Podemos sospechar que la pérdida de vigencia del sistema monetario romano debió de ir haciéndose definitiva a medida que iban desapareciendo los últimos vestigios de la administración provincial. Al fin y al cabo no era ésta si no la que garantizaba el valor de cambio y la utilidad, por tanto, de las pequeñas denominaciones fraccionarias. Sabemos que este proceso fue rápido en las regiones más septentrionales, donde se inicia poco después del otoño del $409^{38}$. Sus efectos debieron de ir haciéndose notar también en el resto del territorio a lo largo del siglo $\mathrm{v}$, ya que para la segunda mitad de esa centuria sólo un sector de la provincia Tarraconense se mantenía bajo el control de la corte imperial establecida en Italia ${ }^{39}$.

37 P.C. Díaz, «El Imperio, los bárbaros y el control sobre la Bética en el siglo v», I Coloquio de Historia Antigua de Andalucía, II, Córdoba, 1993, pp. 317-9.

38 En la Gallaecia la última referencia a un sistema fiscal centralizado se encuentra en la estereotipada cita de Hidacio, 41 [49], a.410 (ed. Burgess, Oxford, 1993, p. 82) sobre la rapiña del exactor: «opes et conditam in urbibus...substantiam...diripit»; cf. P. C.Díaz, «Estructuras de gobierno local en la Antigüedad tardía. Un estudio regional: el N.O. de la Península Ibérica en el siglo v», Studia Zamorensia, 8, 1987, pp. 241-2; sobre el contexto de descomposición del poder imperial en Hispania y su compleja relación con la invasión germánica, ver J. Arce, España entre el mundo antiguo y el mundo medieval, Madrid, 1988, pp. 68-121.

${ }^{39}$ Cf. P.C. Díaz, «El Imperio...», cit. n. 37, pp. 320-3; la provincia, exceptuado el sector noroccidental, se mantiene fiel a Italia hasta el último tercio del siglo v; E.A. Thompson, Romans and Barbarians. The Decline of the Western Empire, Madison, 1982, p. 191. La zona comprendida entre el alto valle del Ebro, el mar Cantábrico y los Pirineos, se sustrajo rápidamente al control romano, posiblemente entre los años 422 (una vez concluida la restauración impulsada desde el sur de la Galia por el patricio Constancio) y 441 , en que Hidacio $(125,128)$ documenta por primera vez las acciones de las baccaudae del área vascona. 
Como consecuencia de esta interrupción casi generalizada del aprovisionamiento de moneda menor en el transcurso del siglo $\mathrm{v}$, se ha hecho ya práctica corriente en la arqueología española y portuguesa la utilización de criterios cronológicos distintos de los que proporcionan las monedas a la hora de fechar un nivel o toda una ocupación tardoantigua. El elemento fundamental de apoyo en esta tarea se encuentra en las cerámicas finas de origen africano, bien conocidas merced a su aparición en otros contextos mediterráneos con monedas y ajuares de los siglos V-VII. No es extraño por tanto que hoy en día se pueda fechar la pérdida de un determinado grupo de monedas dentro de un estrato arqueológico a partir de las cerámicas, en lugar de proceder a la inversa, tal como sucedía en épocas pasadas. Esta manera de actuar tiene importantes implicaciones para la Numismática, ya que hace posible que se pueda abordar el estudio de la perduración del numerario del siglo iv en épocas posteriores. No obstante, también presenta riesgos insoslayables, y no es el menor de ellos el que se deriva de considerar como materiales de uso cotidiano lo que no son sino objetos residuales o amortizados con antelación. Los riesgos se incrementan considerablemente cuando hablamos de monedas que, en pequeño número, forman parte de paquetes estratigráficos muy amplios, con presencia de materiales de cronología diversa y que por su superficialidad hayan podido ser objeto de remoción. No faltan ejemplos en la bibliografía reciente que nos ilustren sobre los problemas interpretativos que generan los contextos arqueológicos. Entre las primeras propuestas de retrasar la formación de depósitos con monedas teodosianas a momentos avanzados del siglo v se encuentra la de los autores del volumen III de las Fouilles de Conimbriga. El hallazgo en esta ciudad de tres pequeños depósitos con moneda del siglo Iv en los niveles de abandono sirvió para plantear la hipótesis de su no recuperación como consecuencia del saqueo sufrido a manos de los suevos en los años 465 y 467 (Hyd. 225; 237). Teniendo en cuenta las alteraciones que presentan los estratos superficiales de los que proceden, esta propuesta no deja de tener un amplio margen de incertidumbre, siendo igualmente posible que las monedas se hubiesen perdido o amortizado en el transcurso de la primera mitad del siglo ${ }^{40}$. En cualquier caso, su no recuperación tuvo que obedecer más a la escasa consideración que merecía el valor metálico contenido en estos depósitos que a su pérdida por ocultación. Mucho más inverosímil es la pretensión de algunos autores de llevar al siglo vi (i!) la formación

${ }^{40}$ Cf. J. Alarcão, R. Etienne, Fouilles de Conimbriga I. L'architecture, París, 1977, pp. 248, 257. de depósitos con una estructura muy homogénea, en la que se incluyen casi exclusivamente aes 2 de época teodosiana. Para ello se suele aducir la asociación de materiales de cronología visigótica, cuando en realidad nos encontramos ante hallazgos que se han producido sin el control arqueológico adecuado o dentro de niveles muy revueltos ${ }^{41}$. Se impone por tanto una gran prudencia a la hora de establecer los límites en los que situar la pérdida de los depósitos aquí comentados.

En el estado actual de nuestros conocimientos parece razonable establecer una línea divisoria entre lo que es la fachada mediterránea de las provincias Tarraconense, Cartaginense y las islas Baleares, donde existe una notable continuidad en los usos monetarios, y el resto de Hispania. La primera de estas dos zonas, cuyo límite hacia el interior habremos de situar probablemente en el valle medio del Ebro, presenta indicios suficientes para pensar en el mantenimiento de la circulación del bronce hasta épocas muy avanzadas, al menos en las ciudades y los centros portuarios, quizás durante toda la Antigüedad tardía ${ }^{42}$. No obstante, hay que hacer notar que dentro de la misma, la importancia ocupada originalmente por el aes 2 teodosiano fue diluyéndose al compás que avanzaba el siglo v. Estas monedas serán un elemento más dentro de un medio muy heterogéneo, en el que ocasionalmente -en las zonas costeras- entraban también los nummi de Teodosio II y Valentiniano III así como las acuñaciones del África vándala. A este respecto, es de destacar la publicación reciente de los hallazgos de Illa de $\mathrm{Cu}$ llera, uno de cuyos conjuntos, de mediados del siglo VI, muestra aún la perduración menor del aes 2: siete ejemplares de estas características sobre un total de cuarenta y seis ${ }^{43}$. No creemos probable, en

${ }^{41}$ Así, disentimos en este punto de las afirmaciones de T. Marot, «Un aspecte de la circulació monetària a la Península Ibèrica en època tardorromana: el comportament anòmal del AE2», Annals de l'Institut d'Estudis Gironins, 37, 19961997, pp. 998-9 a propósito de los depósitos procedentes de El Castillo (Ávila) y Zaragoza. Una interpretación demasiado apresurada del contexto arqueológico es lo que ha llevado sin duda a J. Paz a considerar como del siglo vi el conjunto de diecisiete aes 2 hallado en esta última ciudad. El nivel del que proceden, a juzgar por los materiales que describe el autor, se encuentra muy revuelto, con cerámicas del siglo vi - efectivamente - pero con un dominio de piezas de finales del siglo IV y primera mitad del v.

${ }^{42}$ Resumen de evidencias y bibliografía anterior en $\mathrm{T}$. Marot, «Aproximación a la circulación monetaria en la península Ibérica y las islas Baleares durante los siglos v y vI: la incidencia de las emisiones vándalas y bizantinas», $R N$, 152, 1997, pp. 159-60.

${ }^{43}$ T. Marot, M.M. Llorens, «La circulación monetaria en el siglo vi d.C. en la costa mediterránea: la Punta de l'Illa Cullera (Valencia)», Revista d'Arqueologia de Ponent, 6, 1996, pp. 158-60. 
cambio, que para fechas tan avanzadas hubiese sido fácil reunir acumulaciones de numerario dominadas por esta denominación.

En lo que respecta a la Bética hemos de reconocer que todavía son pocos los datos disponibles sobre la eventual continuidad del uso de la moneda de bronce. El horizonte de depósitos «teodosianos» concuerda aquí perfectamente con una cada vez más nutrida serie de tesoros de solidi de época de Honorio; demasiado bien como para pensar que su formación - al menos en su mayoría - haya superado el comedio del siglo $\mathrm{v}^{44}$. Los datos recopilados recientemente por T. Marot tampoco son concluyentes respecto al mantenimiento en su integridad del sistema de denominaciones romanas. De hecho, en su repertorio se advierte un marcado hiatus, que dura hasta el siglo VI, cuando se hace notar la influencia monetaria bizantina que irradia desde el Sudeste ${ }^{45}$. Los mismos rasgos señalados a propósito de los depósitos de la Bética se vuelven a reconocer entre los hallazgos efectuados en suelo portugués y en la parte de la Lusitania hoy española, muy abundantes y con una estructura homogénea, que sólo parece haber sido posible de conformar cuando aún estaban vigentes los usos inducidos por el aparato administrativo romano. A partir de los años 410 hemos de suponer que en las áreas interiores de la Lusitania y especialmente en el norte de la Península en su conjunto se produjo una rápida involución hacia formas económicas en las que la moneda ocupaba un escaso lugar. La situación social y económica en estos territorios confluía también para hacer menos onerosa la pérdida de importancia del instrumento monetario. Durante el siglo .v amplias áreas de la Península se sustrajeron a su influencia, al verse cada vez más inmersas en un proceso de ruralización, acentuado por el carácter cerrado y frecuentemente autosuficiente de los grandes dominios articuladores del territorio, un fenómeno que iba aparejado al fraccionamiento político que dejaba en herencia la desaparición de la administración provincial ${ }^{46}$. En

${ }^{44}$ El más reciente de estos tesoros es el de Jerez de la Frontera (post 415); Kent, RIC X, p. c.

${ }^{45}$ Cf. T. Marot, «Aproximación...», cit. n. 42, pp. 172-4 y 182-90. El hallazgo de pequeñas cantidades de bronces en contextos arqueológicos que se llevan al siglo vi, en forma de ofrendas depositadas en el interior de sepulturas visigodas, no implica que sobreviviese entonces una economía monetaria desarrollada, ya que ejemplares aislados hạ podido perdurar desprovistos ya de su sentido originario; cf. C.Posac, R.Puertas, La basílica paleocristiana de Vega del Mar, Málaga, 1989, pp. 51-3. En estos casos se trata de ofrendas simples, de uno o dos ejemplares de bronce en un corto número de sepulturas, reminiscencia del rito tradicional que las poblaciones hispanorromanas habían mantenido durante el siglo Iv, el óbolo de Caronte, acrecentado en ocasiones en forma de pequeños depósitos. el ámbito de la villa, el fundus, e incluso en la pequeña comunidad rural dependiente, las necesidades monetarias, ya sólo eventuales, respondían verosímilmente a formas de acumulación o transferencia del excedente, bien como renta o como extracción fiscal residual, una vez que se iban configurando las estructuras de poder germánicas sobre el territorio conquistado. Sus requerimientos se podían cubrir con el solidus y su fracción, el tremissis, tal como confirma su rápida adopción por suevos y visigodos, que harían además de este último un signo de evidente prestigio político.

Este marco teórico, que señala el camino más verosímil seguido por la masa monetaria existente al inicio del siglo $\mathrm{v}$, no ha encontrado sin embargo un refrendo total en la práctica arqueológica, en buena parte debido a las propias dificultades de contextualización de la cultura material de esta época. Existen de todas formas varios indicios que nos demuestran que el bronce había dejado de ser frecuente en los contextos rurales del interior peninsular. Nuestros datos proceden fundamentalmente de la comparación de las cantidades recuperadas en los sitios creados de nueva planta - con motivo de la reordenación del hábitat que se produce ante las condiciones de inseguridad con las que se abre el siglocon las que proporcionan superficies similares habitadas desde la centuria anterior. Tres casos pueden ser traídos aquí a colación. En primer lugar, un castellum recientemente excavado en Buradón (Álava), lugar ocupado como muy pronto a finales del siglo IV y en el que se observa una intensa densidad de espacios domésticos, dispuestos progresivamente durante la centuria siguiente. La superficie excavada alcanza los $1.200 \mathrm{~m}^{2}$ y la zona prospectada es de aproximadamente una hectárea. Esta amplia superficie sólo ha proporcionado cuatro pequeños bronces, en claro contraste con la abundancia del resto de los ajuares recuperados durante su excavación ${ }^{47}$. Otro enclave habitado en el siglo $v$ es el castro de Majaladares, situado en pleno Valle del Ebro ${ }^{48}$. Lo

${ }^{46}$ La manifestación material de esta ruralización se encuentra en las abundantes y en ocasiones lujosas villae que salpican el territorio, particularmente en la Meseta, donde contrastan con un debilitado entramado urbano, vid. P. Palol, «Palencia al final del mundo antiguo», en Actas I Congreso de Historia de Palencia, I, Valladolid, 1987, pp. 349-50; su implantación es un fenómeno característico del siglo IV, con continuidad durante la centuria siguiente, cf. J. Arce, El último siglo de la España romana, Madrid, 1982, pp. 106-9 y 125 .

47 A. Martínez Salcedo, J.J.Cepeda, «Castro de Buradón», en Arqueología de Urgencia, Museo de Arqueología, Vitoria, 1994, pp. 43-60

48 I. Aguilera, «Majaladares (Borja)», en Arqueología 92. Museo de Zaragoza, Zaragoza, 1992, pp. 139, 248-50. 

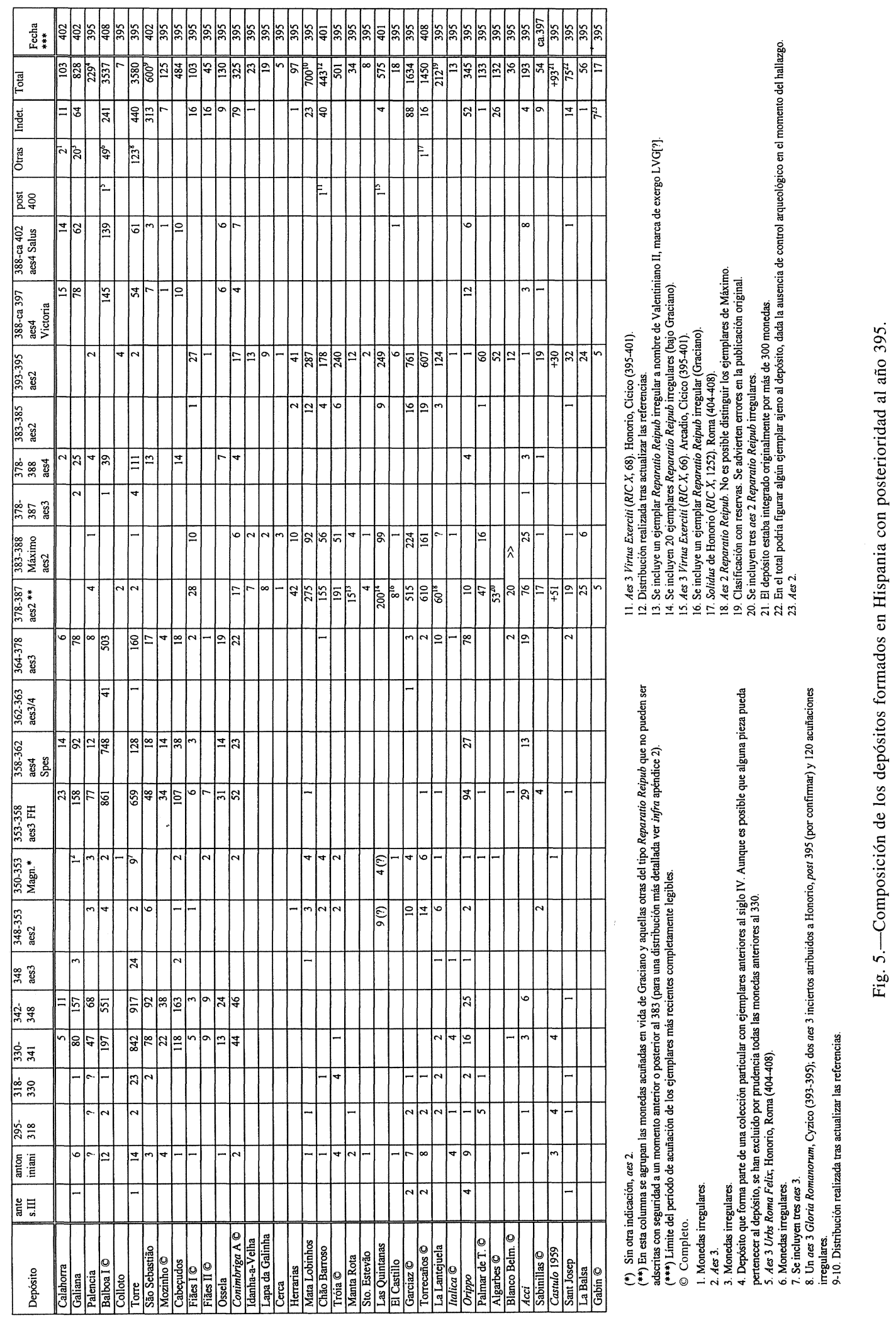
poco que ha sido avanzado sobre su excavación permite comprobar la ausencia total de aes y la aparición, como única moneda, de un tremissis de origen visigodo ${ }^{49}$. La total ausencia de moneda también es llamativa en el castro de El Cristo de San Esteban, en Zamora, excavado en una extensión considerable, que ha permitido a sus autores situar la ocupación a lo largo del siglo $\mathrm{v}^{50}$. Esta sequía de hallazgos contrasta con las 748 monedas recuperadas en la villa de La Olmeda, ocupada ya durante el siglo IV, y en general con la abundancia de los pequeños bronces en la mayor parte de los yacimientos atribuidos al siglo IV ${ }^{51}$.

\section{APÉNDICE 1}

\section{DEPÓSITOS DE AES DE ÉPOCA TEODOSIANA TARDÍA}

Los tesoros y depósitos que se forman con las últimas acunaciones a nombre de Teodosio y sus hijos, conforman uno de los horizontes de acumulación de numerario más nutridos de la Hispania antigua. En su mayor parte se trata de depósitos de aes, aunque no faltan tampoco los conjuntos de solidi emitidos a nombre de Arcadio y Honorio. Aún siendo abundantes, seguimos contando con un número relativamente exiguo de catálogos detallados que faciliten el estudio de este tipo de evidencias. En el apéndice que sigue se recogen los depósitos que están formados con bronces. El lector no encontrará aquí una recopilación exhaustiva de todas las referencias actualmente disponibles, sino simplemente el apoyo bibliográfico que ha sido utilizado para la confección de los cuadros y tablas que acompañan este texto. Sólo para los conjuntos de contenido más abundante (I) y aquellos otros que están integrados por maiorinae (II) hemos pretendido ofrecer un panorama lo más completo posible. En este último apartado se han recogido todas las noticias que nos son conocidas, por muy someras que fuesen. Confiamos en que así pueda valorarse en su justo

49 Se trata de un ejemplar a nombre de Libio Severo $(R I C$ $X, 3758$ ) acuñado posiblemente en Toulouse (461-ca.470).

50 A. Domínguez Bolaños, J. Nuño, «Reflexiones sobre los sistemas defensivos tardoantiguos en la Meseta Norte. A propósito de la muralla de El Cristo de San Esteban, Muela del Pan (Zamora)», en R. Teja, C. Pérez, (eds.), Actas del Congreso Internacional la Hispania de Teodosio, II, Salamanca, 1997, pp. 435-40.

${ }^{51}$ Sobre la villa de La Olmeda, M. Campo, Las monedas..., cit. n. 25 término la singularidad del horizonte monetario peninsular ${ }^{52}$. De forma convencional, se indica con la abreviatura $c a$. que el total de monedas conocido se aproxima al original; el signo (+) señala una cifra mínima, cuando no tenemos constancia de la magnitud del hallazgo.

I. Depósitos CuAntificables con más de CIEn EJEMPLARES EN SU COMPOSICIÓN

CALAHORRA. Calagurris; La Rioja.

300(+); Aes. Hallazgo bajo un derrumbe de tegulae, en las proximidades de otros restos constructivos (mosaico). Se conserva una muestra de 103 ejemplares formando parte de la colección Asociación Amigos de la Historia de Calahorra. Los ejemplares más recientes corresponden a la serie Salus Reipublicae, en aes 4, de los años 395-402. Contenedor perecedero. Contexto arqueológico: extramuros de la ciudad. Relacción habitat: proximidad.

Inédito. Escuetas referencias se encuentran en M. Martín Bueno, M.L. Cancela, «Arqueología clásica de Calahorra y su entorno», Actas del bimilenario de Calahorra, Madrid, 1984 , p. 82 y en U. Espinosa, «El siglo v en el Valle del Ebro: arqueología e historia», Antigüedad y Cristianismo, VIII, Murcia, 1991, p. 278. Información sobre las circunstancias del hallazgo cortesía de la Asociación Amigos de la Historia de Calahorra.

GALIANA. Fuenmayor. La Rioja.

ca. 4.000; Aes. Los más recientes corresponden a la serie Salus Reipublicae, en aes 4 (395-402). Del total originalmente hallado sólo se conservan 828 ejemplares en el Museo de La Rioja, Logroño. Contenedor: indeterminado. Contexto arqueológico: villa. Relación hábitat: proximidad, exterior.

P. Rodríguez, Aproximación a la economía de fines del siglo ov y principios del siglo $v$ en La Rioja: el tesorillo de Galiana, Logroño, 1992; revisión personal.

PALENCIA (provincia de).

242(+); Aes. Los ejemplares más recientes corresponden a la serie oriental, en aes 2, Gloria Romanorum (393-395). Sin datos sobre el tipo de contenedor. Contexto arqueológico indeterminado.

M.C. Lion, «Un tesorillo de bronces del siglo iv procedente de Palencia», BSAA, 50, 1984, pp. 113-56.

BALBOA I (LA HERMIDE). Villarino; Balboa del Bierzo. León.

5.000(+); Aes. Las monedas estaban dispuestas en dos recipientes cerámicos. Se conoce en su integridad el contenido de uno de los conjuntos: 3.537 ejemplares, el más reciente de los cuales corresponde a la serie de Honorio, en aes 3, Urbs Roma Felix (Roma, 404-408). Tesoro. Contexto arqueológico: lugar de habitación indeterminado, situado a media ladera. Relación hábitat: proximidad exterior.

M. Figuerola, «A propósito del Tesoro de Balboa del Bierzo», Numisma, 237, 1996, pp. 225-247.

52 Sólo conocemos dos depósitos fuera de Hispania que se asemejen a los conjuntos recogidos en el catálogo: el hallado en Pest, cerca de Aquincum (65 aes 2 hasta el año 395), publicado A. Alföldi en Der Untergang der Römerherrschaft in Pannonien, Berlín-Leipzig, 1924, pp. 34-40, y el hallado en Priene (Turquía), con 186 aes 2 Gloria Romanorum (393$395)$; Kent, RIC X, p. clvi. 
ALTO DA TORRE. Santa Maria de Émeres; Valpaços. Vila Real. Portugal.

ca. 180.000; Aes (con un número menor de antoniniani) El peso total de lo hallado alcanzaba los $300 \mathrm{~kg}$ aproximadamente. Los ejemplares más recientes (sobre una muestra de 3.165 unidades) son de módulo aes 4 , de la serie Salus Reipublicae acuñada en Italia en el período 388-402 (se señalan algunas monedas que pudieran corresponder a la fase más reciente, aunque las totalmente legibles no sobrepasan el 395). Todo el conjunto forma parte de colecciones particulares. Contenedor cerámico (dolium). Tesoro enterrado. Contexto arqueológico: castro. Relación hábitat: inmediaciones, exterior, a media ladera.

M.C. Hipólito, «Achado monetario de Torre: mais um caso modelar de arqueologia numismática em Portugal», Moeda, 10, 1985, pp. 86-7 y 123-5; E. Alburquerque, «O tesouro monetario do lugar de Torre. Subsidio para o seu estudo», Nummus, 7/8, 1985, pp. 85-129; E. Oliveira, F. Camilio, I. Luna, «Mais dois lotes de moedas do tesouro de Torre (Sta. Maria de Emeres, Valpaços)», Nummus, 9/10, 1987, pp. 115-47; M.J.P. Maciel, T.D.P. Maciel, «O tesouro monetário romano de Santa Maria de Emeres (Valpaços)», Homenagem a Octavio da Veiga Ferreira, Lisboa, 1987, pp. 309-19; R.M.S. Centeno, «Noticia de uma moeda helenística do tesouro de Torre (Santa Maria de Émeres, Valpaços)», Nummus, 11, 1988, pp. 91-3.

OUTEIRO DE SÃo SEBASTIÃo. Palmeira. Braga. Portugal.

4.000(+); Aes (con al menos dos antoniniani). Hallazgo en el interior de un recipiente cerámico. Una muestra de 600 ejemplares se cierra con la serie Salus Reipublicae, en aes 4 (395-402). Contexto arqueológico: altura, hábitat sin confirmar. Paradero desconocido.

M.M. Dos Santos, «Preciso achado arqueológico», $O$ Dis trito de Braga, 2, 1963, pp. 45-51; Fouilles de Conimbriga cit. n. 24 , p. 307 n. $^{\circ} 72$.

MONTE MOZINHO. Oldrões; Penafiel. Oporto. Portugal.

125; Aes (se incluyen también antoniniani y nummi de la familia constantiniana). Ejemplares de módulo aes 3 y aes 4 que se cierran con la serie Salus Reipublicae (los legibles no sobrepasan el 395). Se conserva en el Museo de Penafiel. Contenedor: indeterminado. Contexto arqueológico: castro. Relación hábitat: indeterminada.

I. Pereira, «Achados monetários do Monte Mozinho, Penafiel», Conimbriga 13,1974 , pp. $75-167$.

CABEÇUDOS. Vila Nova de Famalicão. Braga. Portugal.

1209; Aes. Se conocen 484 ejemplares, a partir de un manuscrito dejado por su descubridor. Las monedas son en su mayor parte de módulo aes 3 y aes 4 , que se cierran con las series Victoria auggg y Salus Reipublicae (388-395). Contenedor cerámico. Contexto desconocido.

J. P. de G. Barbosa, «Um tesouro tardirromano de Cabeçudos. V.N. de Famalicão, Braga», en M.P. García-Bellido R.M.S. Centeno (eds.), La moneda hispánica. Ciudad y territorio, Madrid (Anejos AEspA, 14), 1995, pp. 245-52

FIÃES I. Langobriga. Vila da Feira. Aveiro. Portugal.

103; Aes. Las monedas más recientes corresponden a la serie oriental Gloria Romanorum, aes 2 (393-395). Contenedor (?) perecedero. Contexto arqueológico: castro. $\mathrm{Re}$ lación hábitat: interior de un recinto doméstico, nivel de incendio.

R.M.S. Centeno, «Numismática de Fiães: dois tesouros do Baixo Império», Numisma, 138-143, 1976, pp. 176-83.

OSSELA. Oliveira de Azeméis. Aveiro. Portugal.

ca. 130; Aes. Hallazgo contenido en un pequeño recipiente de hierro. Nummi de época tardoconstantiniana, aes 3 y aes
4. Los ejemplares más recientes pertenecen a la serie Salus Reipublicae (388-402). Contexto arqueológico: castro.

A.M..S.P. Silva, F. Teixeira, «Achados numismáticos romanos dos castros de Ossela e de Ul (Oliveira de AzeméisAveiro)» Ul-Vária. Arq.Est.Regionais, 1, 1994, pp. 59-82, A.M..S.P. Silva, J.M.S.M. Pinto, «O tesouro numismático do castro de Ossela (Oliveira de Azeméis)», Ul-Vária. Arq.Est.Regionais, 2, 1995, pp. 53-76.

CONIMBRIGA A. Condeixa-a-Velha. Coimbra. Portugal.

325; Aes (con un reducido número de antoniniani). Los ejemplares más recientes son de módulo aes 2, Gloria Romanorum (393-395). Museo Monográfico de Conimbriga. Contenedor perecedero. Contexto arqueológico: ciudad. Relación hábitat: interior de un recinto, nivel de abandono.

Fouilles de Conimbriga, cit. n. 24, pp. 319-23.

MONTE DE MATA LOBINHOS. Coruche. Santarém. Portugal.

ca.700; Aes. Se reconoce un aurelianus de Probo. Los ejemplares más recientes corresponden a la serie oriental, en aes 2, Gloria Romanorum (393-395). Paradero desconocido. Contenedor: recipiente cerámico. Tesoro enterrado. Contexto arqueológico: poblado en altura. Relación hábitat: interior (embutido en un muro).

J.M.R. Telles, «Achado de moedas romanas», Nummus, 6 , 1961, pp. 146-8; Fouilles de Conimbriga, cit. n. 24, p. 307 $\mathrm{n}^{\circ} 28$.

CHÃO BARROSO. Coruche. Santarém. Portugal.

443(+); Aes. Los ejemplares conocidos son en su mayor parte aes 2; la pieza más reciente es un aes 3 Virtus Exerciti acuñado en Cícico (RIC X, 68; 395-401). Paradero desconocido. Contenedor cerámico, imbrices; las monedas estaban dispuestas en paquetes alineados, cubiertos por dos o tres tejas. Contexto arqueológico: poblado en altura. Relación hábitat: proximidad.

J.M.R. Telles, «Outro achado de moedas romanas em Coruche», Nummus, 11, 1974, pp. 81-7.

TRÓIA. Melides; Grândola. Setúbal. Portugal.

501; Aes. Los ejemplares más recientes corresponden a la serie oriental Gloria Romanorum, aes 2 (393-395). Contenedor: jarra de cerámica común. Contexto arqueológico: ciudad. Relación hábitat: proximidad (hallado en el curso de excavaciones arqueológicas en 1966)

M.L.A. Nunes, «Tesouro de moedas romanas encontradas em Tróia», $A P, 7-9,1974 / 7$, pp. 359-63.

\section{LAS QUINTANAS. Armenteros. Salamanca.}

575(+); Aes 2 en su mayoría. Tesoro hallado en el interior de un recipiente de bronce muy fragmentado. Los ejemplares hoy conservados en el Museo de Salamanca fueron mezclados por su descubridor con un pequeño lote de monedas de cronología anterior no relacionado directamente con el tesoro. Como ejemplar más reciente se reconoce un aes 3 Virtus Exerciti, acuñado en Cícico (RIC X, 66; 395-401). Contexto arqueológico: asentamiento rural indeterminado (posible $v i$ lla). Relación hábitat: proximidad.

M. García Figuerola, «El depósito monetal de las Quintanas, Armenteros (Salamanca)», Numisma, 236, 1995, pp. 65-124.

\section{GARCIAZ. Cáceres.}

1.634; Aes 2 en su mayoría. Los ejemplares más recientes corresponden a la serie oriental Gloria Romanorum (393395). Contenedor perecedero. Tesoro enterrado. Contexto arqueológico: indeterminado. Se conserva en el Museo Provincial de Cáceres.

C. Callejo, «Los bronces romanos de Garciaz», Revista de Estudios Extremeños, 22, 1966, pp. 291-330; Fouilles de Conimbriga, cit. n. 24, p. 306 n $^{\circ} 7$. 
TORRECAÑOS. Guareña. Badajoz.

1.449; Aes 2 en su mayoría. Se incluye también un solidus de Honorio ( $R I C X, 1252$; Roma ca. 404-408) y un anillo de oro. Los ejemplares de bronce más recientes corresponden a la serie oriental Gloria Romanorum (393-395). El conjunto se guarda en el Museo Arqueológico de Badajoz. Contenedor: recipiente perecedero. Contexto arqueológico: villa. Relación hábitat: proximidades, exterior.

A. Velázquez, «El tesorillo de Torrecaños de Guareña (Badajoz). Contribución al estudio de la circulación monetaria durante el Bajo Imperio en el territorium emeritense», $\mathrm{Au}$ gusta Emerita I (EAE 126), Madrid, 1983, pp. 85-190.

\section{LA LANTEJUELA. Sevilla.}

ca. 212; Aes 2 en su mayor parte. El conjunto se cierra con la serie oriental Gloria Romanorum (393-395). Contenedor: indeterminado. Contexto arqueológico indeterminado. Paradero desconocido.

F. Pérez Sindreu, «Tesoro de monedas del Bajo Imperio encontrado en La Lantejuela (Sevilla)», Numisma, 177-179, 1982, pp. $91-110$

ORIPPO. Dos Hermanas. Sevilla.

369; Aes y fragmentos informes. Contenedor de material perecedero. Los ejemplares más recientes corresponden a las series Salus Reipublicae en aes 4 y Gloria Romanorum en aes 2 (393-395). Contexto arqueológico: ciudad. Relación hábitat: interior de un recinto de función indeterminada.

F.J. Velasco, «Tesorillo de bronces bajoimperiales hallado en Orippo (Dos Hermanas, Sevilla)», Gaceta Numismática, 97-98, 1990, pp. 115-24.

PALMAR DE TROYA. Utrera. Sevilla.

133; Aes 2 en su mayor parte. Los ejemplares más recientes corresponden a la serie Gloria Romanorum (393-395). Paradero desconocido. Sin datos sobre el tipo de contenedor. Contexto arqueológico: asentamiento indeterminado. Relación hábitat: inmediaciones (?)

F.J. Velasco, «Tesorillo de bronces bajo-imperiales hallado en El Palmar de Troya (Sevilla)», VII Congreso Nacional de Numismática, Madrid, 1991, pp. 309-28

ALGARBES. Valdevaqueros; Tarifa. Cádiz.

132; Aes. Los ejemplares de más reciente acuñación corresponden a la serie oriental Gloria Romanorum, aes 2 (393-395). Contenedor perecedero. Paradero desconocido. Contexto arqueológico: indeterminado (restos materiales de ocupación en las inmediaciones).

D. Nony, «Un trésor monétaire du Bas-Empire à Tarifa (Cádiz)», MCV, 3, 1967, pp. 93-114; Fouilles de Conimbriga, cit. n. 24, p. $306 \mathrm{n}^{\circ} 1$

\section{ACCI. Guadix. Granada.}

193(+); Aes. Los ejemplares más recientes corresponden a la serie oriental en aes 2 Gloria Romanorum (393-395). Contenedor: recipiente cerámico. Contexto arqueológico: villa suburbana. Relación hábitat: indeterminada.

A. Hueso, «Un tesorillo del siglo IV procedente de la zona accitana», Numisma, 177-179, 1982, pp. 111-41

\section{PeQueños depósitos Y CONJUNTOS MAL CONOCIDOS FORMADOS CON AES 2}

\section{COLlOTO. Pola de Siero. Asturias.}

Numero indeterminado («abundantes»); Aes 2. Se conocen únicamente siete ejemplares, con dominio de la serie Gloria Romanorum oriental (393-395). El conjunto estaba dispuesto ( sin contenedor, aparentemente) entre la fábrica (?) del arco central de descarga de un puente de factura romana (con varias reparaciones).
V. Rodríguez Otero, «El puente romano de Colloto (Asturias)», Zephyrus, 46, 1994, pp. 233-54.

GABÍN Y SEPULCRO. Caesaraugusta; Ciudad de Zaragoza.

17; Aes 2. El conjunto se cierra con la serie oriental Gloria Romanorum (393-395). Contenedor perecedero. Contexto arqueológico: ciudad, recinto de habitación. Relación hábitat: interior («nivel de abandono»). Colección del Museo de Zaragoza.

J. Paz, Cerámica de mesa romana de los siglos III al VI d.C. en la provincia de Zaragoza, Zaragoza, 1991, pp. 24-5.

TARRACO 1857. Ciudad de Tarragona.

ca. 45; Aes 2. Los ejemplares más recientes corresponden a la serie oriental Gloria Romanorum (393-395). Contexto arqueológico: ciudad. Relación hábitat: inmediaciones. Museo Arqueológico de Tarragona.

B. Hernández Sanahuja, A. del Arco, Catálogo del Museo Arqueológico de Tarragona, Tarragona, 1894, pp. 325-6; Fouilles de Conimbriga, cit. n. 24, p. 308 n. 93.

SANT JOSEP. Vall de Uxó. Castellón.

Número indeterminado; Aes. Se conoce una muestra de 75 ejemplares, en su mayoría de época teodosiana: los más recientes corresponden a la serie oriental, en aes 2, Gloria Romanorum (393-395). No hay datos sobre el tipo de contenedor. Contexto arqueológico: poblado en altura, cerro. Relación hábitat: indeterminada, proximidad.

P.P. Ripollés, La circulación monetaria en las tierras valencianas durante la Antigüedad, Barcelona, 1980, pp. 99$104 ;$ J.V. Cavaller, «Conjunt monetari tardo-romà procedent del jaciment de Sant Josep (La Vall d'Uixó)», Cuad. Preh. y Arq. Castellonense, 7, 1980, pp. 299-305.

LA BALSA. Camporrobles. Valencia.

Número indeterminado; Aes 2. Hallazgo en el interior de un recipiente cerámico. Se conoce una pequeña muestra de 56 ejemplares, los más recientes de los cuales son de la serie oriental Gloria Romanorum (393-395). Colección privada. Contexto arqueológico: poblado. Relación hábitat: indeterminada.

P.P. Ripollés, «Hallazgos numismáticos. 1984», Saguntum, 19, 1985, pp. 330-7.

FIÃES II. Langobriga. Vila da Feira. Aveiro. Portugal.

44; Aes. El ejemplar más reciente corresponde a la serie oriental Gloria Romanorum, aes 2 (393-395). Contenedor (?) perecedero. Contexto arqueológico: castro. Relación hábitat: interior de un recinto doméstico, nivel de abandono.

Centeno, cit. supra Fiães, pp. 183-5.

FUNDO DA VILA. Tábua. Coimbra. Portugal.

Número indeterminado; Aes. Se reconocen ejemplares de la serie, en aes 2, Gloria Romanorum (393-395). Contenedor indeterminado. Contexto arqueológico: lugar de habitación indeterminado. Relación hábitat: proximidad.

J. de Alarcão Roman Portugal, II-I, Warminster, 1988, p. 66 n. 314; detalles de la composición, cortesía de C.Lópes.

CONIMBRIGA E. Condeixa-a-Velha. Coimbra. Portugal.

24; Aes. El conjunto se cierra con la serie oriental Gloria Romanorum, en aes 2 (393-395). Museo Monográfico de Conimbriga. Contenedor (?) perecedero. Contexto arqueológico: ciudad. Relación hábitat: interior de un recinto (el mismo que en el depósito A), nivel de abandono.

Fouilles de Conimbriga, cit. n. 24, pp. 327-8.

IDANHA-A-VELHA. Igaeditania. Idanha-a-Nova. Castelo Branco. Portugal.

ca. 2.000; Aes 2 (ca.10 kgs. de peso). Una pequeña muestra de 23 ejemplares se cierra con la serie Gloria Romano- 
rum (393-395). Paradero desconocido. Contenedor indeterminado. Contexto arqueológico: ciudad. Relación hábitat: indeterminada.

Hipólito, cit. supra Alto da Torre, pp. 69-70, n. ${ }^{\circ} 95$; Fouilles de Conimbriga, cit. n. 24, p. 307, n. ${ }^{\circ} 29$.

LAPA DA GALINHA. Alcanena. Santarém. Portugal.

19(+); Aes 2. La muestra conservada en el Museu Nacional de Arqueologia de Lisboa presenta como ejemplares más recientes 9 Gloria Romanorum orientales (393-395). Contenedor indeterminado. Contexto arqueológico desconocido.

M.C. Moreira de Sá, Actas I Congresso Nacional de Ar queologia, Lisboa, 1959, vol.I, p. 127; documentación A.M. Faria.

BARALHAS. Torres Novas. Santarém. Portugal.

Número indeterminado; Aes de Teodosio y Honorio. Contexto arqueológico: asentamiento indeterminado. Paradero desconocido.

P.A. de Azevedo, «Noticias archeologicas do seculo XVIII», $A P, 5,1900$, p. 119 (Información cortesía de A.M. Faria).

TALHADAS. Abrantes. Santarém. Portugal

11(+); Aes 2. Los ejemplares más recientes corresponden a la serie Gloria Romanorum (393-395). Contenedor y contexto arqueológicos indeterminados. Muestra conservada en el Museu Nacional de Arqueologia, Lisboa.

A. Faria, «Guerras e conflitos no Vale do Tejo na Antiguidade: o testemunho dos tesouros monetários», Arqueologia no Vale do Tejo (Catálogo de exposición), Lisboa, 1989, p. 61

LAMEIRANCHA. Alcanena. Santarém. Portugal.

Número indeterminado; Aes. Una pequeña muestra se compone de nummi constantinianos (al menos uno) y aes 2 de las series Reparatio Reipub y Gloria Romanorum (uno de ellos con el tipo de la galera - ca. 383-385- y otro de la serie con labarum, 393-395). Contenedor indeterminado. Contexto arqueológico: lugar de habitación indeterminado.

Inédito. Información proporcionada por A.M.Faria en carta personal, 3-1-1993. Referencia del lugar: J. de Alarcão Ro man Portugal, II-2, Warminster, 1988, p. 114 n. ${ }^{\circ}$ 5/57.

CERCA. Bombarral. Leiria. Portugal.

Número indeterminado; Aes. Una pequeña muestra de 5 ejemplares se cierra con la serie, Gloria Romanorum, aes 2 (393-395). Paradero desconocido. Contenedor: recipiente cerámico. Contexto arqueológico: asentamiento indeterminado. Relación hábitat: proximidad.

Hipólito, cit. supra Alto da Torre, pp. 74-5, n. ${ }^{\circ} 104$; Fouilles de Conimbriga, cit. n. 24, p. 307, n. $^{\circ} 27$.

HERRARIAS. Vila Facaia; Torres Vedras. Lisboa. Portugal 97(+); Aes 2. Los ejemplares más recientes son de la serie Gloria Romanorum (393-395). Contenedor indeterminado. Contexto desconocido.

Inédito. La parte conservada se encuentra en el Museu Nacional de Arqueologia de Lisboa (información cortesía de A. M. Faria, carta personal 3-1-1993).

QUINTA DA BANDEIRA. Loures. Lisboa. Portugal

Número indeterminado; Aes. Se identifican piezas de módulo aes 2, Gloria Romanorum (393-395). Paradero desconocido. Contenedor indeterminado. Contexto arqueológico: indeterminado.

Hipólito, cit. supra Alto da Torre, p. 82, n. ${ }^{\circ} 117$; Fouilles de Conimbriga, cit. n. 24 , p. 307, n. $^{\circ} 26$

MONTE DO MEIO. Capelins. Evora. Portugal.

Número no precisable; Aes 2 y también ejemplares de oro y plata. Se mencionan monedas de Graciano, Arcadio y Honorio. Sin datos sobre el tipo de contenedor. Contexto arqueológico: villa rustica, proximidad indeterminada.
A Viana, «Notas Históricas, Arqueológicas e Etnográfica do Baixo Alentejo», Arquivo de Beja, 16, 1959, p. 43; Fouilles de Conimbriga, cit. n. 24 , p. 307, n. ${ }^{\circ} 20$

SANTA VITORIA. Beja. Portugal.

Número indeterminado; Aes 2. Se citan expresamente ejemplares de Arcadio y Honorio. Paradero desconocido. Contenedor indeterminado. Contexto arqueológico: asentamiento indeterminado. Relación hábitat: inmediaciones.

Hipólito, cit. supra Alto da Torre, p. 85, n. ${ }^{\circ} 126$; Fouilles de Conimbriga, cit. n. 24 , p. 307, n. $^{\circ} 17$

BOCA DO RIO. Vila do Bispo. Faro. Portugal.

$1.000(+) ;$ Aes. Se citan ejemplares de Arcadio y Honorio (aes 2), predominantes en el conjunto. Una parte se conserva en el Museo de Lagos. Contenedor: recipiente cerámico (anforeta). Contexto arqueológico: factoría (pequeño poblado). Relación hábitat: proximidad.

A.Viana, J.Fermosinho, O. da Veiga Ferreira, «De lo prerromano a lo árabe en el Museo Regional de Lagos», AEspA 26, 1953, p. 120; Hipólito, cit. supra Alto da Torre, p. 91 n. ${ }^{\circ}$ 135; M.L.E.V.A. Dos Santos, Arqueologia romana do Al garve, I, Lisboa, 1971, pp. 78-106; Fouilles de Coniimbriga cit. n. 24 , p. 306 , n. 16 ; Alarcão, Roman Portugal, II-3, cit. supra Lameirancha, p. 183, n. $7 / 132$; C. Fabião, «Garum na Lusitania rural? Alguns comentarios sobre o povoamento romano do Algarve», Studia Historica. Historia Antigua, 10$11,1992-1993$, p. 243

SANTO ESTEVÃo. Silves. Faro. Portugal.

Número no precisable; Aes. Aunque parece reconocerse un grupo menor de antoniniani, la mayor parte del conjunto debió de estar integrada por módulos aes 2 de época teodosiana (se señalan Gloria Romanorum orientales de Arcadio y Honorio). Contenedor: recipiente cerámico. Contexto arqueológico: inmediaciones de una mina de cobre. Paradero desconocido.

M.L.E.V.A. Dos Santos, Arqueologia Romana do Algarve, II, Lisboa, 1972, pp. 112-4; Fouilles de Conimbriga, cit. n. 24 , p. 306, n. $^{\circ} 10$

MANTA ROTA. Vila Real de Santo Antonio. Faro. Por tugal.

ca. 750; Aes 2 en su mayoría. El conjunto pesaba aproximadamente $3 \mathrm{~kg}$. Los ejemplares más recientes corresponden a la serie oriental Gloria Romanorum (393-395). Contenedor cerámico. Contexto arqueológico: asentamiento indeterminado. Relación hábitat: indeterminada. Paradero desconocido.

Inédito. Información cortesía de A. M. Faria, que pudo examinar 34 monedas (carta personal, 1-3-1993). El lugar es citado por Alarcão, Roman Portugal, II-3, cit. supra Lameirancha, p. 206, n. $^{\circ} 8 / 296$.

EL CASTILLO. Diego Álvaro. Ávila.

18; Aes 2 en su mayoría. Posiblemente se trate de la totalidad de un pequeño depósito, que se cierra con la serie oriental Gloria Romanorum. Sin datos sobre el contenedor. Contexto: asentamiento rural con hábitat continuado en los siglos VI-VII.

M. Abad Varela, «Depósito monetario procedente de El Castillo (Diego Álvaro) en el Museo de Ávila», Cuadernos Abulenses, 16, 1991, 171-88.

LOS CASARES. La Nava de Ricomalillo. Toledo.

Número indeterminado; Aes 2. Contenedor de material perecedero; las piezas se presentaban unidas entre sí por el óxido, formando pequeños paquetes. Únicamente se conoce la descripción de una muestra reducida: aes 2 de Graciano (dos ejemplares), aes 2 de Arcadio (dos ejemplares, tipo Gloria Romanorum, 393-395), y Honorio (un ejemplar del mismo tipo). Contexto arqueológico: lugar de habitación indeterminado. Relación hábitat: imprecisable. 


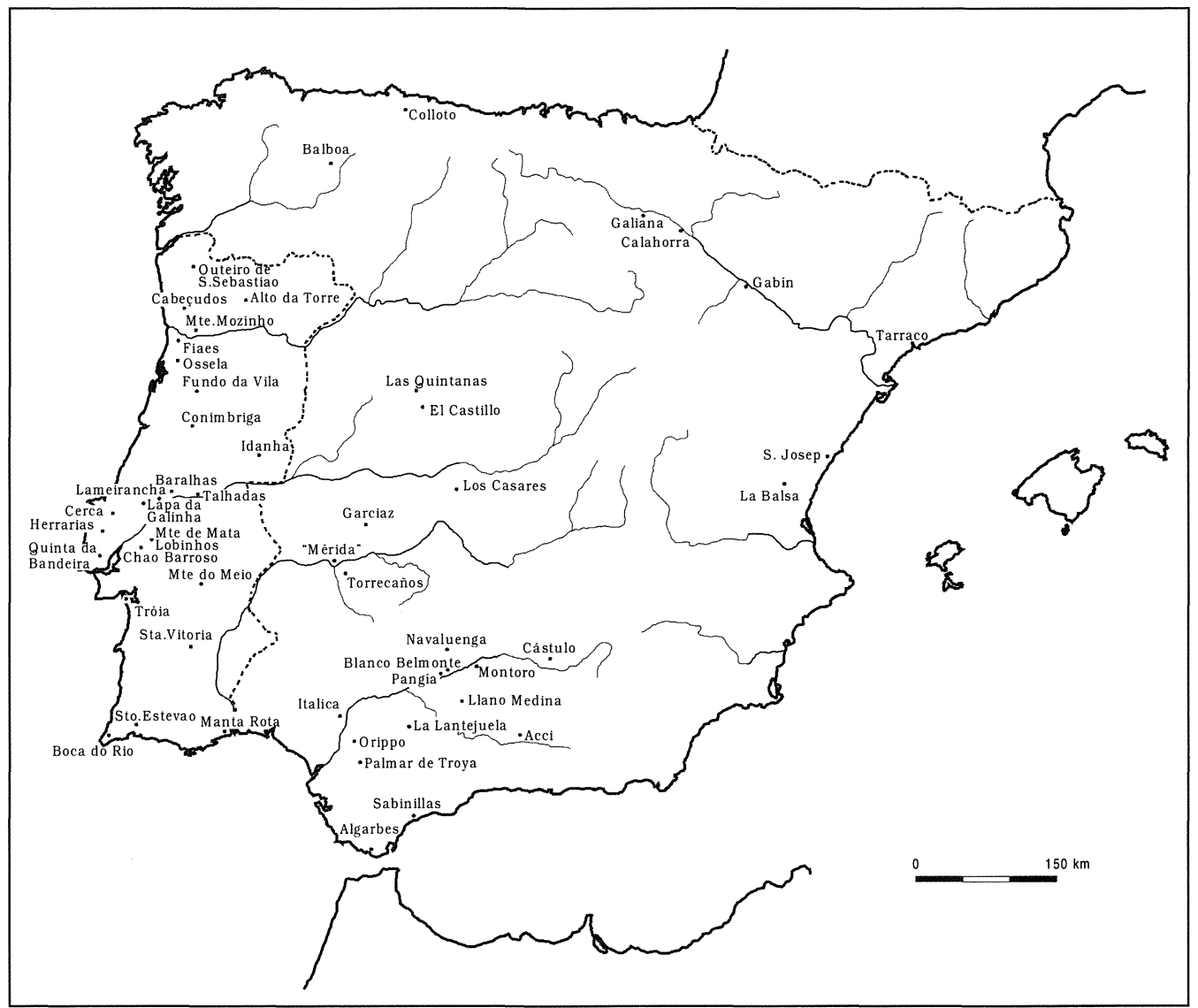

Fig. 6.-Depósitos de aes de época teodosiana tardía incluidos en el catálogo.

F. Jiménez de Gregorio, «Monedas romanas de la Nava de Ricomalillo», AEspA, 23, 1950, pp. 191-2.

«MÉRIDA», alrededores de. Badajoz.

ca. 250; Aes 2 de época teodosiana. Los ejemplares más recientes corresponden a la serie oriental Gloria Romanorum (393-395). Paradero desconocido. Contenedor indeterminado. Contexto arqueológico: indeterminado. El contenido de este depósito lo pudimos observar fugazmente en el mercado de antigüedades de Bilbao, antes de su dispersión, en octubre de 1989.

Inédito.

CASTULO, 1959. Linares. Jaén.

300(+) Aes 2 en su mayoría. El conjunto se cierra con la serie oriental Gloria Romanorum (393-395). Contenedor: recipiente de cobre. Contexto arqueológico: ciudad. Relación hábitat: inmediaciones.

M. Calzado, «El tesorillo monetal hallado en Cástulo en 1959», Oretania, 2, 1960, pp. 280-2.

NAVALUENGA. Villanueva de Córdoba. Córdoba

ca. 1.300; Aes. Una pequeña muestra de cinco ejemplares se compone exclusivamente de módulos aes 2 , teodosianos (el más reciente corresponde a la serie oriental Gloria Romanorum, 393-395).Otros 800 ejemplares se conservan aún en una colección de Navaluenga (información cortesía de Raquel Gil). Contenedor: indeterminado. Tesoro. Contexto arqueológico desconocido.
A. García y Bellido, «Restos de un tesorillo monetario descubierto en Villanueva de Córdoba», AEspA, 30, 1957, pp. 114-5.

BLANCO BELMONTE. Corduba. Ciudad de Córdoba.

36; Aes 2 en su mayoría. Los ejemplares más recientes son de la serie Gloria Romanorum (393-395). Recuperado en el curso de una excavación de urgencia. Contenedor perecedero.

L. Aparicio Sánchez, «Dos excavaciones arqueológicas de urgencia en la C/ Blanco Belmonte de Córdoba», Anuario Arqueológico de Andalucía, III, Actividades de Urgencia, Sevilla, 1992, pp. 224-234. Detalles sobre la composición cortesía de R. Gil.

MONTORO. Epora. Córdoba.

ca. 4000; Aes 2 en su mayoría. El tesoro fue hallado en el transcurso de unas obras efectuadas en el casco urbano de la localidad. Dominan las acuñaciones de Máximo, Teodosio, Arcadio y Honorio; también se citan ejemplares de Constantino. Los reversos más recientes son los de la serie oriental Gloria Romanorum (393-395). Se conserva en el Museo Arqueológico de Córdoba. Contenedor: recipiente cerámico. Contexto arqueológico: ciudad. Relación hábitat: indeterminada.

L. Mapelli, «Tesoro de Montoro: bronces del siglo IV», Gaceta Numismática, 45, 1977, pp. 38-42. Actualmente en estudio por R. Gil, a cuya generosidad debemos los datos provisionales sobre el contenido. 
PANGÍA. Córdoba.

ca. 750; Aes 2. Tesoro que se cierra con la serie Gloria Romanorum (393-395). Tipo de contenedor desconocido. Contexto arqueológico: establecimiento rural indeterminado. Inédito. Información cortesía de R. Gil.

LLANO MEDINA. Doña Mencía. Córdoba.

78; Aes 2 en su mayoría, de los tipos Reparatio Reipub y Gloria Romanorum (393-395). Se conserva en el Museo de Doña Mencía. Contenedor perecedero. Contexto: establecimiento rural indeterminado.

J. Jiménez Urbano, «Un tesorillo de monedas romano encontrado en Llano Medina», El Bermejino, 126, 1990, p. 9. Información sobre el contenido cortesía de R. Gil.

ITALICA, Traianeum. Santiponce. Sevilla.

13 Aes (se incluyen antoniniani y nummi). El ejemplar más reciente es un aes 2 Gloria Romanorum: Cícico, $L R B C$ 2571 (393-395). Contenedor perecedero (pequeña bolsa: las monedas estaban alineadas de canto). Contexto arqueológico: ciudad, edificio público reutilizado como vivienda precaria. Relación hábitat: interior, sobre el suelo.

F. Chaves, «Hallazgos numismáticos», en P. León Traianeum de Italica, Sevilla, 1988, pp. 121-37.

SABINILLAS/«MANILVA». Manilva. Málaga.

54; Aes. El ejemplar más reciente es de la serie Victoria Augg en aes 4 (Tréveris, 395-ca. 397). Contenedor perecedero. Contexto arqueológico: villa. Relación hábitat: sobre el mosaico de una de las estancias y bajo el derrumbe del techo (nivel de abandono o destrucción).

P. Rodríguez Oliva, «El tesorillo de bronces bajo-imperiales de Manilva (Málaga)», XV CNA, Zaragoza, 1979, p. 835 .

APÉNDICE 2

DEPÓSITOS DE AES 2.

DISTRIBUCIÓN DE LAS SERIES DE LOS AÑOS 378-395 POR TIPOS Y CECAS

SANT JOSEP. Vall de Uxó; Castellón.

\begin{tabular}{|l|r|r|r|r|r|r|r|r|r|r|r|r|r|r|r|r|}
\hline Reverso & Tr & Lug & Arl & Rm & Aq & Sis & Thes & Her & Cpl & Nic & Cyz & Ant & Al & Indet & Total & $\%$ \\
\hline $\begin{array}{l}\text { Reparatio } \\
\text { 378-383 }\end{array}$ & & & 2 & 3 & 4 & & 3 & & & & & & & & 1 & 13 \\
\hline $\begin{array}{l}\text { Reparatio } \\
\text { Máximo 383-386 }\end{array}$ & 1 & & & & & & & & & & & & & 5 & 6 & \\
\hline $\begin{array}{l}\text { Victoria Augg } \\
\text { Máximo 386-387 }\end{array}$ & 1 & & & & & & & & & & & & & 1 & \\
\hline $\begin{array}{l}\text { Gloria Romanorum } \\
\text { "Galera" 383-385 }\end{array}$ & & & & & & & & & & & & 1 & & & 1 & \\
\hline Subtotal & 1 & 1 & 2 & 3 & 4 & & 3 & & & & & 1 & & & 6 & 21 \\
\hline $\begin{array}{l}\text { Gloria Romanorum } \\
\text { 393-395 }\end{array}$ & & & & & & & & & 4 & 6 & 7 & 6 & 2 & 70 & 32 & 60 \\
\hline Total & 1 & 1 & 2 & 3 & 4 & & 3 & & 4 & 6 & 7 & 7 & 2 & 13 & 53 & \\
\hline
\end{tabular}

Porcentaje respecto al total clasificable: $87 \%$

LA BALSA. Camporrobles; Valencia.

\begin{tabular}{|l|r|r|r|r|r|r|r|r|r|r|r|r|r|r|r|r|}
\hline Reverso & Tr & Lug & Arl & Rm & Aq & Sis & Thes & Her & Cpl & Nic & Cyz & Ant & Al & Indet & Total & $\%$ \\
\hline \hline $\begin{array}{l}\text { Reparatio } \\
378-383\end{array}$ & & 2 & 3 & 5 & 3 & 3 & 3 & & & & & 3 & & 3 & 25 & \\
\hline $\begin{array}{l}\text { Reparatio } \\
\text { Máximo 383-386 }\end{array}$ & 1 & & 1 & & & & & & & & & & & 4 & 6 & \\
\hline Subtotal & 1 & 2 & 4 & 5 & 3 & 3 & 3 & & & & & 3 & & 7 & 31 & 56 \\
\hline $\begin{array}{l}\text { Gloria Romanorum } \\
\text { 393-395 }\end{array}$ & & & $:$ & & & & & 4 & 6 & & 4 & 5 & & 5 & 24 & 44 \\
\hline Total & 1 & 2 & 4 & 5 & 3 & 3 & 3 & 4 & 6 & & 4 & 8 & & 12 & 55 & \\
\hline
\end{tabular}

Porcentaje respecto al total clasificable: $\iota$ ? 
FIÃES I. Vila da Feira. Portugal.

\begin{tabular}{|l|r|r|r|r|r|r|r|r|r|r|r|r|r|r|r|r|}
\hline Reverso & Tr & Lug & Arl & Rm & Aq & Sis & Thes & Her & Cpl & Nic & Cyz & Ant & Al & Indet & Total & $\%$ \\
\hline \hline $\begin{array}{l}\text { Reparatio } \\
378-383\end{array}$ & & 3 & 1 & & 2 & 4 & & & & & & 3 & & 4 & 17 & \\
\hline $\begin{array}{l}\text { Reparatio } \\
378-386\end{array}$ & & & & & & & & & & & & & & 12 & 12 & \\
\hline $\begin{array}{l}\text { Reparatio } \\
\text { Máximo 383-386 }\end{array}$ & 3 & 3 & & & & & & & & & & & 3 & 9 & \\
\hline $\begin{array}{l}\text { Virtus Exerciti } \\
\text { ca. 385 }\end{array}$ & & & & & & & & & 1 & & & & & 1 & \\
\hline Subtotal & & 6 & 4 & & 2 & 4 & & & & 1 & & 3 & & 19 & 39 & 59 \\
\hline $\begin{array}{l}\text { Gloria Romanorum } \\
\text { 393-395 }\end{array}$ & & & & & & & & 3 & 2 & 6 & 5 & 7 & & 4 & 27 & 41 \\
\hline Total & & 6 & 4 & & 2 & 4 & & 3 & 2 & 7 & 5 & 10 & & 23 & 66 & \\
\hline
\end{tabular}

Porcentaje respecto al total clasificable: $76 \%$

TRÓIA. Setúbal. Portugal.

\begin{tabular}{|l|r|r|r|r|r|r|r|r|r|r|r|r|r|r|r|r|}
\hline Reverso & Tr & Lug & Arl & Rm & Aq & Sis & Thes & Her & Cpl & Nic & Cyz & Ant & Al & Indet & Total & $\%$ \\
\hline \hline $\begin{array}{l}\text { Reparatio } \\
378-383\end{array}$ & 3 & 19 & 39 & 65 & 17 & 17 & 9 & & 1 & 2 & & 10 & 1 & 8 & 191 & \\
\hline $\begin{array}{l}\text { Reparatio } \\
\text { Máximo 383-386 }\end{array}$ & 3 & 14 & 34 & & & & & & & & & & & & 51 & \\
\hline $\begin{array}{l}\text { Salus Reipublicae } \\
\text { 383-385 }\end{array}$ & & & & & & & & & 1 & & & & & & 1 & \\
\hline $\begin{array}{l}\text { Virtus Exerciti } \\
\text { ca. 385 }\end{array}$ & & & & & & & & 2 & 2 & & & 1 & & & 5 & \\
\hline Subtotal & 6 & 73 & 65 & 17 & 17 & 9 & 2 & 4 & 2 & & 11 & 1 & 8 & 248 & 51 \\
\hline $\begin{array}{l}\text { Gloria Romanorum } \\
\text { 393-395 }\end{array}$ & & & & & & & & 28 & 49 & 65 & 27 & 61 & 10 & & 240 & 49 \\
\hline Total & 6 & 33 & 73 & 65 & 17 & 17 & 9 & 30 & 53 & 67 & 27 & 72 & 11 & 8 & 488 & \\
\hline
\end{tabular}

Porcentaje respecto al total clasificable: $97 \%$

LAS QUINTANAS. Armenteros; Salamanca.

\begin{tabular}{|l|r|r|r|r|r|r|r|r|r|r|r|r|r|r|r|r|}
\hline Reverso & Tr & Lug & Arl & Rm & Aq & Sis & Thes & Her & Cpl & Nic & Cyz & Ant & Al & Indet & Total & $\%$ \\
\hline $\begin{array}{l}\text { Reparatio } \\
378-383\end{array}$ & 2 & $20+2$ & $27+7$ & $58+1$ & 14 & 9 & 17 & & 2 & 14 & & 5 & & $17+2$ & $185+12$ & \\
\hline $\begin{array}{l}\text { Reparatio } \\
378-386\end{array}$ & & $3+1$ & $4+1$ & & & & & & & & & & & $13+5$ & $20+7$ & \\
\hline $\begin{array}{l}\text { Reparatio } \\
\text { Máximo 383-386 }\end{array}$ & 5 & 24 & 53 & & & & & & & & & & & 15 & 97 & \\
\hline $\begin{array}{l}\text { Victoria Augg } \\
\text { Máximo 386-387 }\end{array}$ & & 1 & 1 & & & & & & & & & & & & 2 & \\
\hline $\begin{array}{l}\text { Gloria Romanorum } \\
\text { "Galera" 383-385 }\end{array}$ & & & & & & & & 1 & & 2 & & & & & 3 & \\
\hline $\begin{array}{l}\text { Salus Reipublicae } \\
\text { 383-385 }\end{array}$ & & & & & & 1 & & & & & 1 & & & & 2 & \\
\hline $\begin{array}{l}\text { Virtus Exerciti } \\
\text { ca. 385 }\end{array}$ & & & & & & & & 1 & 2 & & & & & & 3 & \\
\hline Subtotal & 7 & $48+3$ & $85+8$ & $58+1$ & 14 & 10 & 17 & 2 & 4 & 16 & 1 & 5 & & $45+7$ & $312+19$ & 57,1 \\
\hline $\begin{array}{l}\text { Gloria Romanorum } \\
\text { 393-395 }\end{array}$ & & & & & & & & 24 & $44+1$ & 45 & 29 & 60 & 17 & $28+1$ & $247+2$ & 42,9 \\
\hline Total & 7 & $48+3$ & $85+8$ & $58+1$ & 14 & 10 & 17 & 26 & $48+1$ & 61 & 30 & 65 & 17 & $73+8$ & $559+21$ & \\
\hline
\end{tabular}

Con el signo + se distinguen las acuñaciones irregulares

Porcentaje respecto al total clasificable: $i$ ? 
GARCIAZ. Cáceres.

\begin{tabular}{|l|r|r|r|r|r|r|r|r|r|r|r|r|r|r|r|r|}
\hline Reverso & Tr & Lug & Arl & Rm & Aq & Sis & Thes & Her & Cpl & Nic & Cyz & Ant & Al & Indet & Total & $\%$ \\
\hline $\begin{array}{l}\text { Reparatio } \\
\text { 378-383 }\end{array}$ & 6 & 40 & 52 & 113 & 54 & 31 & 20 & & & 2 & & 30 & 4 & 163 & 515 & \\
\hline $\begin{array}{l}\text { Reparatio } \\
\text { Máximo 383-386 }\end{array}$ & 20 & 33 & 107 & & & & & & & & & & & 64 & 224 & \\
\hline $\begin{array}{l}\text { Gloria Romanorum } \\
\text { "Galera" 383-385 }\end{array}$ & & & & & & & & & & & & & & 8 & 8 & \\
\hline $\begin{array}{l}\text { Salus Reipublicae } \\
\text { 383-385 }\end{array}$ & & & & & & & & & 2 & & & 1 & & & 3 & \\
\hline $\begin{array}{l}\text { Virtus Exerciti } \\
\text { ca.385 }\end{array}$ & & & & & & & & & & & & 3 & & 1 & 4 & \\
\hline Subtotal & 26 & 73 & 159 & 113 & 54 & 31 & 20 & & 2 & 2 & & 34 & 4 & 236 & 754 & 50 \\
\hline $\begin{array}{l}\text { Gloria Romanorum } \\
\text { 393-395 }\end{array}$ & & & & & & & & 84 & 157 & 174 & 84 & 159 & 19 & 82 & 759 & 50 \\
\hline Total & 26 & 73 & 159 & 113 & 54 & 31 & 20 & 84 & 159 & 176 & 84 & 193 & 23 & 318 & 1513 & \\
\hline
\end{tabular}

Porcentaje respecto al total clasificable: $98 \%$

TORRECAÑOS. Guareña; Badajoz.

\begin{tabular}{|c|c|c|c|c|c|c|c|c|c|c|c|c|c|c|c|c|}
\hline Reverso & $\mathrm{Tr}$ & Lug & Arl & $\mathrm{Rm}$ & $\mathrm{Aq}$ & Sis & Thes & Her & $\mathrm{Cpl}$ & Nic & Cyz & Ant & $\overline{\mathrm{Al}}$ & Indet & Total & $\%$ \\
\hline $\begin{array}{l}\text { Reparatio } \\
378-383\end{array}$ & 3 & 22 & 49 & 66 & 41 & 30 & 21 & & 2 & 3 & & 32 & 2 & 182 & 453 & \\
\hline $\begin{array}{l}\text { Reparatio } \\
378-386 \\
\end{array}$ & 2 & 7 & 26 & & & & & & & & & & & 122 & 157 & \\
\hline $\begin{array}{l}\text { Reparatio } \\
\text { Máximo 383-386 }\end{array}$ & 4 & 30 & 45 & & & & & & & & & & & 82 & 161 & \\
\hline $\begin{array}{l}\text { Gloria Romanorum } \\
\text { "Galera" 383-385 }\end{array}$ & & & & & & & & & 2 & 1 & & 2 & & 1 & 6 & \\
\hline $\begin{array}{l}\text { Gloria Romanorum } \\
\text { "Cautivo" 383-385 }\end{array}$ & & & & & & & & & & & & 1 & & 1 & 2 & \\
\hline $\begin{array}{l}\text { Salus Reipublicae } \\
383-385\end{array}$ & & & & & & & & 1 & 1 & & & 1 & & & 3 & \\
\hline $\begin{array}{l}\text { Virtus Exerciti } \\
\text { ca. } 385\end{array}$ & & & & & & & & 2 & & 1 & 1 & 1 & & 4 & 9 & \\
\hline Subtotal & 9 & 59 & 120 & 66 & 41 & 30 & 21 & 3 & 5 & 5 & 1 & 37 & 2 & 391 & 791 & 56 \\
\hline $\begin{array}{l}\text { Gloria Romanorum } \\
\text { 393-395 }\end{array}$ & & & & & & & & 27 & 119 & 85 & 31 & 112 & 22 & 211 & 607 & 44 \\
\hline Total & 9 & 59 & 120 & 66 & 41 & 30 & 21 & 30 & 124 & 90 & 32 & 149 & 24 & 602 & 1398 & \\
\hline
\end{tabular}

Porcentaje respecto al total clasificable: $97 \%$

PALMAR DE TROYA. Sevilla.

\begin{tabular}{|c|c|c|c|c|c|c|c|c|c|c|c|c|c|c|c|c|}
\hline Reverso & $\mathrm{Tr}$ & Lug & Arl & $\mathrm{Rm}$ & $\mathrm{Aq}$ & Sis & Thes & Her & Cpl & Nic & Cyz & Ant & $\mathrm{Al}$ & Indet & Total & $\%$ \\
\hline $\begin{array}{l}\text { Reparatio } \\
378-383 \\
\end{array}$ & 2 & 4 & 5 & 4 & 1 & 3 & 1 & & 2 & & & 4 & & 13 & 39 & \\
\hline $\begin{array}{l}\text { Reparatio } \\
378-386 \\
\end{array}$ & & & 2 & & & & & & & & & & & 6 & 8 & \\
\hline $\begin{array}{l}\text { Reparatio } \\
\text { Máximo 383-386 } \\
\end{array}$ & & & 7 & & & & & & & & & & & 8 & 15 & \\
\hline $\begin{array}{l}\text { Victoria Augg } \\
\text { Máximo, 386-387 }\end{array}$ & & & 1 & & & & & & & & & & & & 1 & \\
\hline $\begin{array}{l}\text { Virtus Exerciti } \\
\text { ca.385 }\end{array}$ & & & & & & & & & & 1 & & & & & 1 & \\
\hline Subtotal & 2 & 4 & 15 & 4 & 1 & 3 & 1 & & 2 & 1 & & 4 & & 27 & 64 & 52 \\
\hline $\begin{array}{l}\text { Gloria Romanorum } \\
\text { 393-395 }\end{array}$ & & & & & & & & 8 & 13 & 9 & 7 & 7 & 1 & 15 & 60 & 48 \\
\hline Total & 2 & 4 & 15 & 4 & 1 & 3 & 1 & 8 & 15 & 10 & 7 & 11 & 1 & 42 & 124 & \\
\hline
\end{tabular}

Porcentaje respecto al total clasificable: $93 \%$ 
ALGARBES. Tarifa; Cádiz.

\begin{tabular}{|c|c|c|c|c|c|c|c|c|c|c|c|c|c|c|c|c|}
\hline Reverso & $\mathrm{Tr}$ & Lug & Arl & $\mathrm{Rm}$ & $\mathrm{Aq}$ & Sis & Thes & Her & $\mathrm{Cpl}$ & $\mathrm{Nic}$ & Cyz & Ant & $\mathrm{Al}$ & Indet & Total & $\%$ \\
\hline $\begin{array}{l}\text { Reparatio } \\
378-383\end{array}$ & & $3+1$ & & 3 & 1 & & & & & & & & & 9 & $16+1$ & \\
\hline $\begin{array}{l}\text { Reparatio } \\
378-386\end{array}$ & 1 & 1 & 5 & & & & & & & & & & & $27+2$ & $34+2$ & \\
\hline Subtotal & 1 & $4+1$ & 5 & 3 & 1 & & & & & & & & & $36+2$ & $50+3$ & 50 \\
\hline $\begin{array}{l}\text { Gloria Romanorum } \\
393-395\end{array}$ & & & & & & & & & 6 & 4 & & 5 & & 37 & 52 & 50 \\
\hline Total & 1 & $4+1$ & 5 & 3 & 1 & & & & 6 & $\overline{4}$ & & 5 & & $73+2$ & $102+3$ & \\
\hline
\end{tabular}

Porcentaje respecto al total clasificable: $99 \%$

ACCI. Guadix; Granada.

\begin{tabular}{|c|c|c|c|c|c|c|c|c|c|c|c|c|c|c|c|c|}
\hline Reverso & $\operatorname{Tr}$ & Lug & Arl & $\mathrm{Rm}$ & $\mathrm{Aq}$ & Sis & Thes & Her & Cpl & Nic & Cyz & Ant & $\mathrm{Al}$ & Indet & Total & $\%$ \\
\hline $\begin{array}{l}\text { Reparatio } \\
378-383 \\
\end{array}$ & 1 & 4 & 16 & 24 & 13 & 8 & 1 & & & & & 1 & 1 & 7 & 76 & \\
\hline $\begin{array}{l}\text { Reparatio } \\
\text { Máximo 383-386 }\end{array}$ & 1 & 3 & 17 & & & & & & & & & & & 4 & 25 & \\
\hline Subtotal & 2 & 7 & 33 & 24 & 13 & 8 & 1 & & & & & 1 & 1 & 11 & 101 & 99 \\
\hline $\begin{array}{l}\text { Gloria Romanorum } \\
393-395\end{array}$ & & & & & & & & 1 & & & & & & & 1 & 1 \\
\hline Total & 2 & 7 & 33 & 24 & 13 & 8 & 1 & 1 & & & & 1 & 1 & 11 & 102 & \\
\hline
\end{tabular}

Porcentaje respecto al total clasificable: $54 \%$

\section{SABINILLAS. Manilva; Málaga.}

\begin{tabular}{|c|c|c|c|c|c|c|c|c|c|c|c|c|c|c|c|c|}
\hline Reverso & $\operatorname{Tr}$ & Lug & Arl & $\mathrm{Rm}$ & $\mathrm{Aq}$ & Sis & Thes & Her & $\mathrm{Cpl}$ & Nic & Cyz & Ant & $\mathrm{Al}$ & Indet & Total & $\%$ \\
\hline $\begin{array}{l}\text { Reparatio } \\
378-383\end{array}$ & & 1 & 2 & 1 & 1 & 1 & 1 & & & & & 1 & & 7 & 15 & \\
\hline $\begin{array}{l}\text { Reparatio } \\
378-386\end{array}$ & & 1 & 1 & & & & & & & & & & & & 2 & \\
\hline $\begin{array}{l}\text { Reparatio } \\
\text { Máximo 383-386 }\end{array}$ & & & 1 & & & & & & & & & & & & 1 & \\
\hline Subtotal & & 2 & 4 & 1 & 1 & 1 & 1 & & & & & 1 & & 7 & 18 & 49 \\
\hline $\begin{array}{l}\text { Gloria Romanorum } \\
393-395\end{array}$ & & & & & & & & 2 & 4 & 2 & 2 & 5 & & 4 & 19 & 51 \\
\hline Total & & 2 & 4 & 1 & 1 & 1 & 1 & 2 & 4 & 2 & 2 & 6 & & 11 & 37 & \\
\hline
\end{tabular}

Porcentaje respecto al total clasificable: $82 \%$

\section{APÉNDICE 3}

\section{LA ACUÑACIÓN DE LA MAIORINA GLORIA ROMANORUM (393-395)}

1. TIPO, CECAS Y EMISIONES

La leyenda Gloria Romanorum adoptada en los aes 2 del período 393-395 es una muestra bien re- presentativa del uso reiteradamente propagandístico y muy poco renovado de los reversos monetarios durante la segunda mitad del siglo Iv. Su aparición, extremadamente frecuente en las monedas acuñadas 
a lo largo de esos años, se asocia casi siempre a la iconografía heroica y triunfante del Emperador. En el caso que nos ocupa, éste aparece representado como dueño absoluto del orbe romano, acompañado de un estandarte en cuya parte superior se entrevé la representación muy esquematizada del cristograma constantiniano, bien en la forma de una sencilla cruz de San Andrés o bajo el aspecto de una estrella. El labarum o vexillum personal del Emperador es en esta época uno de sus atributos militares más característicos. Muy común desde las acuñaciones de los sucesores inmediatos de Constantino, es adoptado luego por los príncipes de la casa teodosiana como forma más usual de destacar la virtud y el fundamento cristiano de su poder. En Occidente dará lugar al tipo característico de los solidi acuñados en el período 394-425, en los que el Emperador figura como un sublimis signifer, que se yergue sobre los enemigos del orden romano ${ }^{53}$.

Los ejemplares hallados en Hispania constituyen sin duda el material más abundante hoy disponible para conocer cómo se articula la serie de reversos Gloria Romanorum en el interior de las cecas

${ }^{53}$ J.P.C. Kent, RIC X, p. 56; la expresión es de Claudiano, de VI consulatu Honorii, 22. que producen aes 2 en los últimos años del reinado de Teodosio. Los datos cuantitativos recogidos en nuestra revisión de los depósitos publicados, y especialmente, durante nuestro examen de la colección del Museo Arqueológico Nacional de Madrid, permiten completar el esquema de las emisiones tal como fue propuesto por Pearce y retocado posteriormente por los autores del Late Roman Bronze Coinage. Nuestro interés se centrará aquí en la distribución del volumen de moneda acordado en cada taller a los tres augustos de la casa teodosiana - Teodosio, Arcadio y Honorio - y en la determinación de la importancia de las distintas emisiones individualizadas. Para ello hemos confeccionado en primer lugar una serie de cuadros en los que se resumen los datos disponibles ${ }^{54}$.

${ }^{54}$ Datos procedentes de los siguientes depósitos: Fiães III, Troia, Las Quintanas, Garciaz, Torrecaños, Palmar, Algarbes, Sabinillas, Sant Josep, La Balsa. Hallazgos de circulación: Fouilles de Conimbriga, cit. n. 24, passim. Los ejemplares del Museo Arqueológico Nacional de Madrid han sido estudiados directamente. Se trata de 653 monedas procedentes seguramente de hallazgos imprecisos dentro del territorio español. Aprovechamos la ocasión para agradecer la ayuda prestada en todo momento por la directora de la Sección de Numismática de este museo, Dña. Carmen Alfaro Asins.

\section{Heraclea}

1. Depósitos y hallazgos de circulación.

\begin{tabular}{|c|c|c|c|c|c|}
\hline \multirow{2}{*}{$\begin{array}{l}\text { Emisión (según } \\
L R B C \text { ) }\end{array}$} & \multirow{2}{*}{ Anversos } & \multicolumn{3}{|c|}{ Officinae } & \multirow{2}{*}{ Total } \\
\hline & & A & B & ¿? & \\
\hline \multirow[t]{5}{*}{$--/ /$ SMHA } & Teodosio & 25 & 27 & 7 & 59 \\
\hline & Arcadio & 21 & 14 & 1 & 36 \\
\hline & Honorio & 20 & 14 & 1 & 35 \\
\hline & Indeterminado & 2 & 1 & & 3 \\
\hline & Total & 68 & 56 & 9 & 133 \\
\hline \multirow[t]{5}{*}{-*//SMHA } & Teodosio & 13 & 8 & 1 & 22 \\
\hline & Arcadio & 9 & 8 & & 17 \\
\hline & Honorio & 4 & 6 & 4 & 14 \\
\hline & Indeterminado & & 1 & & 1 \\
\hline & Total & 26 & 23 & 5 & 54 \\
\hline
\end{tabular}

2. Colección del Museo Arqueológico Nacional.

\begin{tabular}{|c|c|c|c|c|c|}
\hline \multirow{2}{*}{$\begin{array}{l}\text { Emisión (según } \\
L R B C \text { ) }\end{array}$} & \multirow{2}{*}{ Anversos } & \multicolumn{3}{|c|}{ Officinae } & \multirow{2}{*}{ Total } \\
\hline & & A & B & i? & \\
\hline \multirow[t]{4}{*}{$--/ /$ SMHA } & Teodosio & 12 & 4 & & 16 \\
\hline & Arcadio & 8 & 2 & 1 & 11 \\
\hline & Honorio & 2 & & 1 & 3 \\
\hline & Total & 22 & 6 & 2 & 30 \\
\hline \multirow[t]{4}{*}{-*//SMHA } & Teodosio & 12 & 10 & & 22 \\
\hline & Arcadio & 13 & 11 & 2 & 26 \\
\hline & Honorio & 11 & 6 & & 17 \\
\hline & Total & 36 & 27 & 2 & 65 \\
\hline
\end{tabular}


Constantinopolis

1. Depósitos y hallazgos de circulación.

\begin{tabular}{|c|c|c|c|c|c|c|c|}
\hline \multirow{2}{*}{$\begin{array}{l}\text { Emisión (según } \\
L R B C \text { ) }\end{array}$} & \multirow{2}{*}{ Anversos } & \multicolumn{5}{|c|}{ Officinae } & \multirow{2}{*}{ Total } \\
\hline & & $\mathrm{A}$ & $\mathrm{B}$ & $\Gamma$ & $\Delta$ & $i ?$ & \\
\hline \multirow[t]{5}{*}{- -//CONSA } & Teodosio & 134 & 53 & 3 & 9 & 15 & 214 \\
\hline & Arcadio & 3 & 1 & 59 & 5 & 13 & 81 \\
\hline & Honorio & 9 & 1 & 2 & 59 & 6 & 77 \\
\hline & Indeterminado & 2 & & & & 8 & 10 \\
\hline & Total & 148 & 55 & 64 & 73 & 42 & 382 \\
\hline$--/ / C O N S A \bullet$ & Arcadio & 1 & & & & & 1 \\
\hline \multirow[t]{4}{*}{$++/ /$ CONSA } & Teodosio & 7 & 2 & & & 5 & 14 \\
\hline & Arcadio & & & 6 & & 1 & 7 \\
\hline & Honorio & 1 & & & 6 & . & 7 \\
\hline & Total & 8 & 2 & 6 & 6 & 6 & 28 \\
\hline
\end{tabular}

2. Colección del Museo Arqueológico Nacional.

\begin{tabular}{|c|c|c|c|c|c|c|c|}
\hline \multirow{2}{*}{$\begin{array}{l}\text { Emisión (según } \\
L R B C \text { ) }\end{array}$} & \multirow{2}{*}{ Anversos } & \multicolumn{5}{|c|}{ Officinae } & \multirow{2}{*}{ Total } \\
\hline & & A & B & $\Gamma$ & $\Delta$ & $i ?$ & \\
\hline \multirow[t]{4}{*}{$--/ /$ CONSA } & Teodosio & 60 & 10 & 1 & & 5 & 76 \\
\hline & Arcadio & 1 & & 23 & 1 & 3 & 28 \\
\hline & Honorio & & & & 14 & 1 & 15 \\
\hline & Total & 61 & 10 & 24 & 15 & 9 & 119 \\
\hline$--/ / \mathrm{CONSA} \bullet$ & Teodosio & & 1 & & & & 1 \\
\hline \multirow[t]{4}{*}{$++/ /$ CONSA } & Teodosio & 11 & 1 & & & & 12 \\
\hline & Arcadio & & & 6 & & & 6 \\
\hline & Honorio & & & & 8 & & 8 \\
\hline & Total & 11 & 1 & 6 & 8 & & 26 \\
\hline
\end{tabular}

Nicomedia

1. Depósitos y hallazgos de circulación.

\begin{tabular}{|c|c|c|c|c|c|c|c|}
\hline \multirow{2}{*}{$\begin{array}{l}\text { Emisión (según } \\
L R B C \text { ) }\end{array}$} & \multirow{2}{*}{ Anversos } & \multicolumn{5}{|c|}{ Officinae } & \multirow{2}{*}{ Total } \\
\hline & & A & B & $\Gamma$ & ¿Q? & ¿? & \\
\hline \multirow[t]{5}{*}{$--/ /$ SMNA } & Teodosio & 127 & 9 & 9 & 1 & 9 & 155 \\
\hline & Arcadio & 18 & 82 & 2 & 2 & 17 & 121 \\
\hline & Honorio & 5 & 17 & 104 & & 2 & 128 \\
\hline & Indeterminado & 5 & 3 & 1 & & 2 & 11 \\
\hline & Total & 155 & 111 & 116 & 3 & 30 & 415 \\
\hline -*//SMNA & Teodosio & 3 & & & & 1 & 4 \\
\hline
\end{tabular}

2. Colección del Museo Arqueológico Nacional.

\begin{tabular}{|c|c|c|c|c|c|c|}
\hline \multirow{2}{*}{$\begin{array}{l}\text { Emisión (según } \\
L R B C \text { ) }\end{array}$} & \multirow{2}{*}{ Anversos } & \multicolumn{4}{|c|}{ Officinae } & \multirow{2}{*}{ Total } \\
\hline & & A & B & $\Gamma$ & $i ?$ & \\
\hline \multirow[t]{4}{*}{$--/ /$ SMNA } & Teodosio & 48 & & 1 & 2 & 51 \\
\hline & Arcadio & 4 & 35 & & 5 & 44 \\
\hline & Honorio & 1 & & 19 & & 20 \\
\hline & Total & 53 & 35 & 20 & 7 & 115 \\
\hline \multirow[t]{4}{*}{-米//SMNA } & Teodosio & 2 & & & & 2 \\
\hline & Arcadio & 1 & & & 1 & 2 \\
\hline & Honorio & & & 1 & 1 & 2 \\
\hline & Total & 3 & & 1 & 2 & 6 \\
\hline
\end{tabular}


Cyzicus

1. Depósitos y hallazgos de circulación.

\begin{tabular}{|c|c|c|c|c|c|c|c|}
\hline \multirow{2}{*}{$\begin{array}{l}\text { Emisión (según } \\
L R B C \text { ) }\end{array}$} & \multirow{2}{*}{ Anversos } & \multicolumn{5}{|c|}{ Officinae } & \multirow{2}{*}{ Total } \\
\hline & & A & $\mathrm{B}$ & $\Gamma$ & $i \Delta ?$ & ¿? & \\
\hline \multirow[t]{5}{*}{$--/ / \mathrm{SMKA}$} & Teodosio & 24 & 28 & 4 & 1 & 1 & 58 \\
\hline & Arcadio & 28 & 17 & 31 & & 3 & 79 \\
\hline & Honorio & 22 & 11 & 32 & & 3 & 68 \\
\hline & Indeterminado & & 1 & 1 & & & 2 \\
\hline & Total & 74 & 57 & 68 & 1 & 7 & 207 \\
\hline
\end{tabular}

2. Colección del Museo Arqueológico Nacional.

\begin{tabular}{|c|c|c|c|c|c|c|}
\hline \multirow{2}{*}{$\begin{array}{l}\text { Emisión (según } \\
L R B C \text { ) }\end{array}$} & \multirow{2}{*}{ Anversos } & \multicolumn{4}{|c|}{ Officinae } & \multirow{2}{*}{ Total } \\
\hline & & A & B & $\Gamma$ & i? & \\
\hline \multirow[t]{4}{*}{$--/ /$ SMKA } & Teodosio & 13 & 13 & 11 & 6 & 43 \\
\hline & Arcadio & 20 & 15 & 22 & 2 & 59 \\
\hline & Honorio & 7 & 3 & 14 & & 24 \\
\hline & Total & 40 & 31 & 47 & 8 & 126 \\
\hline
\end{tabular}

Antiochia

1. Depósitos y hallazgos de circulación.

\begin{tabular}{|c|c|c|c|c|c|c|c|}
\hline \multirow{2}{*}{$\begin{array}{l}\text { Emisión (según } \\
L R B C \text { ) }\end{array}$} & \multirow{2}{*}{ Anversos } & \multicolumn{5}{|c|}{ Officinae } & \multirow{2}{*}{ Total } \\
\hline & & $\mathrm{A}$ & B & $\Gamma$ & $\Delta$ & ¿? & \\
\hline \multirow[t]{5}{*}{$--/ /$ ANTA } & Teodosio & 125 & 4 & 3 & 19 & 10 & 161 \\
\hline & Arcadio & 7 & 85 & 4 & 8 & 6 & 110 \\
\hline & Honorio & 9 & 1 & 102 & 36 & 9 & 157 \\
\hline & Indeterminado & 7 & 3 & & 2 & 4 & 16 \\
\hline & Total & 148 & 93 & 109 & 65 & 29 & 444 \\
\hline$--/ /$ ANA & Honorio & & & 2 & & & 2 \\
\hline
\end{tabular}

2. Colección del Museo Arqueológico Nacional.

\begin{tabular}{|l|l|r|r|r|r|r|r|}
\hline \multirow{2}{*}{$\begin{array}{l}\text { Emisión (según } \\
L R B C \text { ) }\end{array}$} & \multirow{2}{*}{ Anversos } & \multicolumn{7}{|c|}{ Officinae } & \multirow{2}{*}{ Total } \\
\cline { 3 - 8 } & & $\mathrm{A}$ & $\mathrm{B}$ & $\Gamma$ & $\Delta$ & \multicolumn{1}{c|}{$i ?$} & \\
\hline$--/ /$ ANTA & Teodosio & 47 & 1 & 3 & 7 & & 58 \\
\hline & Arcadio & & 29 & 2 & 4 & 9 & 44 \\
\hline & Honorio & 2 & & 21 & 7 & 3 & 33 \\
\hline & Total & $\mathbf{4 9}$ & $\mathbf{3 0}$ & $\mathbf{2 6}$ & $\mathbf{1 8}$ & $\mathbf{1 2}$ & $\mathbf{1 3 5}$ \\
\hline
\end{tabular}

Alexandria

1. Depósitos y hallazgos de circulación.

\begin{tabular}{|l|l|r|r|r|r|}
\hline \multirow{2}{*}{$\begin{array}{l}\text { Emisión (según } \\
\text { LRBC) }\end{array}$} & \multirow{2}{*}{ Anversos } & \multicolumn{3}{|c|}{ Officinae } & \multirow{2}{*}{ Total } \\
\cline { 3 - 6 } & & $\mathrm{A}$ & $\mathrm{B}$ & \multicolumn{1}{c|}{ ? } & \\
\hline$--/ /$ ALEA & Teodosio & 9 & 12 & 4 & 25 \\
\hline & Arcadio & 14 & 9 & 1 & 24 \\
\hline & Honorio & 12 & 6 & 2 & 20 \\
\hline & Indeterminado & 1 & 1 & & 2 \\
\hline & Total & $\mathbf{3 6}$ & $\mathbf{2 8}$ & $\mathbf{7}$ & $\mathbf{7 1}$ \\
\hline
\end{tabular}

2. Colección del Museo Arqueológico Nacional.

\begin{tabular}{|c|c|c|c|c|c|}
\hline \multirow{2}{*}{$\begin{array}{l}\text { Emisión (según } \\
L R B C \text { ) }\end{array}$} & \multirow{2}{*}{ Anversos } & \multicolumn{3}{|c|}{ Officinae } & \multirow{2}{*}{ Total } \\
\hline & & A & B & ¿? & \\
\hline$--/ /$ ALEA & Teodosio & $\overline{8}$ & 4 & 1 & 13 \\
\hline & Arcadio & 7 & 4 & 2 & 13 \\
\hline & Honorio & 4 & & & 4 \\
\hline & Total & 19 & 8 & 3 & 30 \\
\hline
\end{tabular}

Distribución general. Cecas orientales

\begin{tabular}{|l|r|}
\hline Teodosio & 1006 \\
\hline Arcadio & 709 \\
\hline Honorio & 634 \\
\hline Indeterminado & 45 \\
\hline Total & $\mathbf{2 3 9 4}$ \\
\hline
\end{tabular}


En líneas generales los talleres orientales respetan una jerarquía bastante precisa en la atribución de los anversos a las diferentes officinae en funcionamiento, según un modelo progresivamente implantado en la acuñación a lo largo del siglo Iv. Teodosio, el Augustus senior, es frecuentemente el destinatario de la actividad desarrollada en la primera de las dependencias, mientras Arcadio y Honorio ocupan en este orden las demás. La excepción destacable la constituyen las cecas que reducen a menos de tres el número de officinae y distribuyen consiguientemente el numerario según proporciones preestablecidas. Un caso aparte lo encontramos en Cícico, que muestra un patrón aparentemente más errático que el que se observa en el resto de talleres de la Propóntida, ya que las tres dependencias identificadas trabajan indistintamente para los tres augustos.

Dando representatividad al resultado que se obtiene de los datos numéricos aquí manejados, podemos resumir los aspectos más destacables del funcionamiento de las cecas del siguiente modo:

- En la cantidad total de moneda emitida, Teodosio destaca sobre sus dos hijos al corresponderle aproximadamente un tercio más de la cantidad que les es destinada individualmente.

- En el juego de las oficinas, la A refuerza su jerarquía con un número de monedas que es casi siempre superior al de las demás, en todos los talleres.

- El rango inferior que, por antigüedad, corresponde a Honorio - aclamado en Constantinopla en enero del 393- se reconoce frecuentemente al serle destinada una oficina inferior en orden a la de Arcadio, pero no tanto en la cantidad total de moneda emitida a su nombre ya que las cifras suelen ser muy parecidas para los dos augustos. Esta relativa proporcionalidad confirma igualmente que la acuñación de la serie Gloria Romanorum no se inicia hasta después de su nombramiento, posiblemente algunos meses más tarde, si aceptamos, como lo hace recientemente Kent, su no solapamiento con los aes 4 Salus Reipublicae, que -en Oriente-pudieron haber dejado de fabricarse entonces ${ }^{55}$.

55 Kent, «Coinage of Arcadius..», cit. n. 31, p. 49; como argumento se aduce la baja proporción de anversos de Honorio en los aes 4 orientales y la unidad de leyenda de los tipos introducidos en el 393: aes 2 y aes 3 Gloria Romanorum (este último con un reverso característico de adventus: emperador a caballo con la mano derecha alzada). Hasta ahora se admitía generalmente la acuñación simultánea de las tres denominaciones, fundamentada en la similitud de las marcas de exergo (cf. $L R B C I I$, p. 89,2186 ss.; entre otras), una base poco sólida, dada la simplicidad y reiteración de los diferenciadores durante estos años. En cualquier caso, los tres valores se integraban en un sistema de equivalencias metálicas $1: 2: 4$ y mantenían como patrón respectivo el 1/60,1/120 y $1 /$ 240 de libra, con una amplia tolerancia en la acuñación real.
El reconocimiento de una serie de rasgos generales no debe hacernos olvidar la existencia de importantes variaciones de detalle en el funcionamiento de los distintos talleres, tal como tendremos ocasión de destacar a continuación.

\section{Heraclea}

Sus dos officinae producen para los tres augustos. El resultado netamente favorable a Teodosio se consigue especialmente en la emisión —//SMHA, en la segunda dependencia del taller, en una proporción que podría estimarse de 2:1 respecto a la asignada a cada uno de sus hijos. Al igual que sucede en otros talleres de la Propóntida, nos encontramos con dos emisiones, ordenadas según la complejidad del diferenciador. La que coincide con la introducción del tipo es, como suele ser habitual, la de mayor volumen ${ }^{56}$.

En lo que respecta a la plasmación concreta del tipo de reverso adoptado en esta serie, podemos decir que los productos de Heraclea se reconocen bien por la utilización de una variante que le es propia. Nos referimos a la terminación superior del estandarte, que adopta aquí una forma triangular muy marcada (fig. 7.1).

\section{Constantinopla}

La ceca de la capital y corte de Teodosio es la que - quizá como refuerzo de su posición simbólica- reproduce con más rigor un esquema jerárquico en la organización de las acuñaciones. Podemos reconocer perfectamente cómo se destinan las dos primeras oficinas a Teodosio, mientras la tercera y la cuarta trabajan para Arcadio y Honorio respectivamente. Como consecuencia de la importancia alcanzada por el volumen de moneda salido de la primera - entre el doble y el triple del reservado a las oficinas $\Gamma$ y $\Delta-$ los anversos de Teodosio llegan a superar a la suma de los destinados a Arcadio y Honorio.

De los cuatro diferenciadores de emisión señalados por Pearce, sólo el primero parece haber correspondido a una producción de envergadura. No obstante, los hallazgos permiten reconocer cómo en una de las emisiones menores - la que incluye dos

${ }^{56}$ Una excepción aparente a este comportamiento general se encuentra en la colección del MAN, donde es más abundante la emisión -S//SMHA, pero ello puede deberse simplemente a la selección practicada en la muestra antes de su ingreso en el museo. 
cruces en el campo- se mantiene aún el esquema adoptado inicialmente.

La ceca de la corte oriental se caracteriza también por presentar la versión más cuidada y completa del tipo de reverso. Ello se aprecia especialmente en la forma de confeccionar el estandarte que sujeta el emperador, cuyo motivo central es una forma esquemática del labarum constantiniano. El estandarte quiere representar así la imagen de un crismón rodeado de perlas, bajo la apariencia de una estrella de ocho o seis puntas y no simplemente un aspa como sucede en el resto de los talleres (fig. 7.3-4).

\section{Nicomedia}

Como en Heraclea, encontramos también aquí dos emisiones, aunque la segunda, que utiliza el mismo signo adoptado en el taller tracio, debió de ser poco importante. Tradicionalmente se ha admitido que la ceca trabaja durante estos años con cuatro oficinas, de las cuales, la última sólo estaría operativa ocasionalmente ${ }^{57}$. La evidencia aquí reunida es aclaradora al respecto. Unicamente tres ejemplares son atribuibles a la officina $\Delta$ entre los hallazgos publicados, y ninguno entre los conservados en la colección del MAN. Podemos dudar por tanto de la correcta identificación de los primeros. En realidad creemos que deben ser desechados, ya que seguramente son producto de malas lecturas. La confusión obedece en parte a la forma que adopta la alfa en los exergos de las monedas, con el trazo central oblicuo, que en ocasiones puede llevar a confusión con el numeral $\Delta$ (fig. 7.5; también en Cícico: fig. 7.8). A tenor de las cifras, el taller de Nicomedia trabajó por tanto, a lo largo de este período, con sólo tres dependencias.

El patrón de la emisión principal adopta la jerarquía de los augustos como criterio de asignación: la A para Teodosio, la B para Arcadio y la $\Gamma$ para Honorio, con escasas excepciones. En Nicomedia, como en Cícico, la introducción de los aes 2 y aes 3 Gloria Romanorum va acompañada de la utilización exclusiva de la leyenda de anverso con cesura para Arcadio, lo que refuerza el carácter sucesivo de la serie respecto a los aes 4 Salus Reipublicae (siempre con leyenda continua).

57 Cf. $L R B C$ II, p. 107 n. 2368 (sin embargo, en n. 2422 incluyen los Gloria Romanorum entre las producciones con dos officinae, situación que con seguridad no se da hasta el 395 , si no posteriormente); cf. ahora Kent, RIC X, p. 69.

\section{Cícico}

La única emisión conocida se realiza en tres officinae - la pieza catalogada con marca $\Delta$ debe responder a una mala lectura- que trabajan indistintamente para los tres augustos. No obstante, de seguir los resultados que ofrecen los depósitos publicados, se puede reconocer un patrón más preciso en la tercera dependencia, que destina la mayor parte de su producción a Arcadio y Honorio. El sistema de asignar proporciones preestablecidas para cada emperador, en cada una de las oficinas, es característico de esta ceca, a pesar de que su número permitía el empleo del patrón jerárquico más corriente. Un proceder semejante se puede reconocer ya desde el 383 y se encontrará de nuevo a la muerte de Teodosio, cuando la serie Virtus Exerciti se acuñe indistintamente para Arcadio y Honorio en las dos oficinas que quedan en uso ${ }^{58}$.

\section{Antioquía}

La ceca del Orontes, muy activa a final de siglo, produce una sola emisión - eso sí muy abundantede reversos Gloria Romanorum (fig. 7.9-10). No creemos que la marca - //ANA, individualizada en el $L R B C$, defina un grupo separado; dos ejemplares aislados, reconocidos en los depósitos aquí manejados no nos parecen suficientes para modificar la opinión de Pearce, que veía en este exergo un error de composición de la marca corriente - //ANTA ${ }^{59}$. La distribución de los anversos mantiene la jerarquía ya conocida, aunque la cuarta oficina se destina de forma preferente a Honorio, que ya disponía de la tercera; una situación que se anticipa al reparto que será característico desde el 395: A y B para Arcadio, $\Gamma$ y $\Delta$ para Honorio. Es privativo de esta ceca la utilización de bustos con diadema de rosetas en el anverso. Su frecuencia es algo inferior a la de la diadema de perlas, común al resto de los talleres.

\section{Alejandría}

Sin duda es éste el taller de más baja y tosca producción. La tosquedad se advierte sobre todo en la mala transcripción de las leyendas, pero también

${ }^{58}$ Pearce, RIC IX, p. 238; Kent, «Coinage of Arcadius..», cit. n. 31 , p. 50

${ }^{59}$ RIC IX, p. 294, n. 68(e). Errores semejantes en la composición de los exergos se pueden reconocer en dos monedas del depósito Las Quintanas: cf. M. Figuerola, «El depósito...», cit. n. 8, n. ${ }^{\text {os }} 423$ (Antioquía) y 511(Constantinopla). 


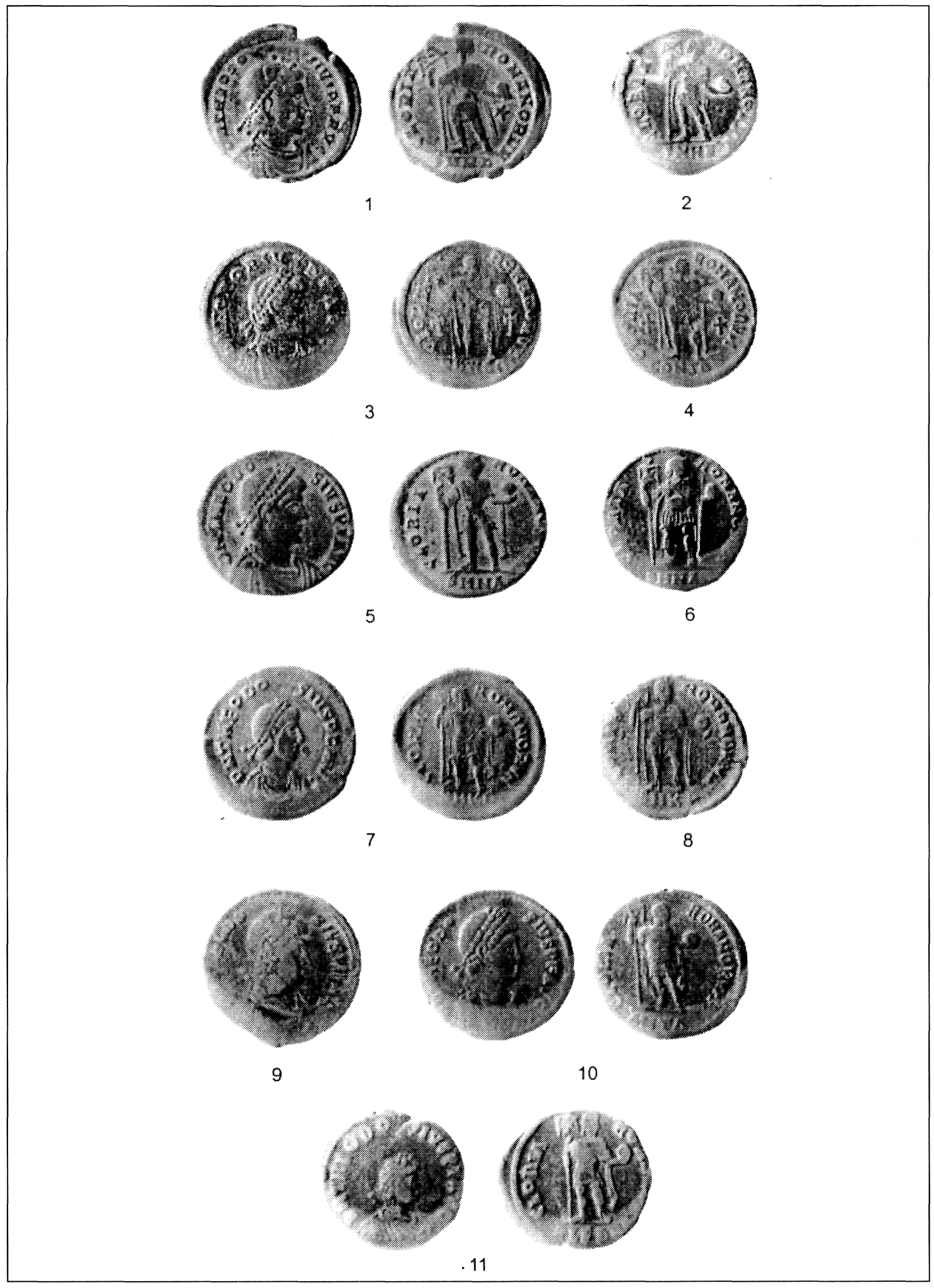

Fig. 7.-Aes 2 Gloria Romanorum, 393-395. 


\begin{tabular}{|l|c|c|c|c|c|c|}
\hline & \multicolumn{3}{|c|}{ Ceca } & ANT & ALE \\
\cline { 2 - 7 } & HER & CPL & NIC & CYZ & 4,71 & 4,75 \\
\hline Peso medio & 5,07 & 5,21 & 4,92 & 4,87 & 85 & 21 \\
\hline Ejemplares & 56 & 85 & 81 & 85 & 21 \\
\hline
\end{tabular}

Fig. 8.-Peso medio (en gramos) de los aes 2 Gloria Romanorum (393-395) conservados en el Museo Arqueológico Nacional de Madrid. Se excluyen los ejemplares con alteración o fuerte desgaste.

en el descuido con el que son asignados los bustos de los tres augustos, al no guardar su tamaño una relación clara con la posición ocupada por cada uno de ellos (fig. 7.11). El aes 2 se produjo en las dos primeras oficinas, mientras la tercera se encargaba de la producción de aes 3 .

\section{Pesos (fig. 8)}

Aunque se ha asumido generalmente que la maiorina mantuvo a final de siglo su peso teórico de $1 / 60$ de libra $(5,38 \mathrm{~g}$ según el valor Naville de $322,56 \mathrm{~g}$ ), no hemos contado hasta fechas recientes con información suficiente que pudiera confirmar$10{ }^{60}$. Pocos son, en efecto, los depósitos publicados que incluyen datos metrológicos precisos y, cuando ello es así, nos encontramos por lo general con muestras poco representativas. Tan sólo el depósito de las Quintanas ofrece en la actualidad un listado suficientemente amplio de reversos Gloria Romanorum susceptible de ser utilizado con este fin. Tenemos así que, sobre 236 ejemplares allí incluidos, el peso medio resultante es de 4,58 g. La cifra está claramente por debajo del patrón teórico estimado para la serie, pero ello puede estar motivado sin más por la inclusión, en el total manejado, de una elevada proporción de monedas alteradas ${ }^{61}$. Un resultado si- milar se observa también en la muestra conservada en el Museo Arqueológico Nacional, que proporciona un peso medio de $4,54 \mathrm{~g}$ sobre un total de 653 monedas. Sin embrago, en este caso sí hemos podido efectuar un cálculo alternativo, una vez descontados los ejemplares que mostraban alteraciones - por corrosión, fragmentación o perforación intencionadas- o tenían signos de fuerte desgaste, y situarnos así ante valores mucho más próximos a lo que debió de ser la realidad original. Una vez aplicado este criterio la muestra se reduce a 413 ejemplares, con un peso medio de $4,94 \mathrm{~g}$, apenas un $8 \%$ inferior al teórico $1 / 60$ y perfectamente asumible dentro de los parámetros de tolerancia que se reconocen en las acuñaciones del siglo IV. Por talleres, el valor más alto lo proporciona Constantinopla, con 5,21g, mientras el más bajo corresponde a Antioquía, con 4,71 g ${ }^{62}$.

\section{Procedencia de las fotografías}

Sección de Numismática del Museo Arqueológico Nacional, salvo figura 1, números 1, 3 (Tesoro de Torrecaños, Museo de Badajoz) y 5 (Tesoro de Navaluenga).
${ }^{60}$ Cf. Depeyrot, «Le système monétaire...», cit. n. 3, pp. 84-5.

${ }_{61}$ Los pesos que se obtienen a partir de las cecas mejor representadas no difieren mucho del resultado general: 4,57 $\mathrm{g}$ en Constantinopla (43); 4,73 g en Nicomedia (44); 4,50 g en Antioquía (58). Estas cifras son suficientes, en cualquier caso, para desechar la utilización del patrón a 1/72 de libra $(4,48 \mathrm{~g})$, empleado durante la acuñación de la serie Fel Temp Reparatio en el 348.
${ }^{62}$ Por obvias limitaciones de espacio no reproducimos aquí los datos correspondientes a cada uno de los ejemplares catalogados. El listado se encuentra depositado en la sección de Numismática del MAN. 